RENATA SANTAREM DE OLIVEIRA

ASSOCIAÇÕES GENÓTIPO-FENÓTIPO EM 29 PORTADORES DE HIPERPLASIA ADRENAL CONGÊNITA FORMA CLÁSSICA ACOMPANHADOS EM UM CENTRO DE REFERÊNCIA DO DISTRITO FEDERAL: UM ESTUDO RETROSPECTIVO LONGITUDINAL 


\author{
UNIVERSIDADE DE BRASÍLIA \\ FACULDADE DE CIÊNCIAS DA SAÚDE \\ PROGRAMA DE PÓS-GRADUAÇÃO EM CIÊNCIAS DA SAÚDE
}

RENATA SANTAREM DE OLIVEIRA

ASSOCIAÇÕES GENÓTIPO-FENÓTIPO EM 29 PORTADORES DE HIPERPLASIA ADRENAL CONGÊNITA FORMA CLÁSSICA ACOMPANHADOS EM UM CENTRO DE REFERÊNCIA DO DISTRITO FEDERAL: UM ESTUDO RETROSPECTIVO LONGITUDINAL

Dissertação apresentada como requisito parcial para obtenção do Título de Mestre em Ciências da Saúde pelo Programa de Pós-Graduação em Ciências da Saúde da Universidade de Brasília.

Orientadora: Profa. Dra. Adriana Lofrano Alves-Porto

BRASÍLIA 


\title{
ASSOCIAÇÕES GENÓTIPO-FENÓTIPO EM 29 PORTADORES DE HIPERPLASIA ADRENAL CONGÊNITA FORMA CLÁSSICA ACOMPANHADOS EM UM CENTRO DE REFERÊNCIA DO DISTRITO FEDERAL: UM ESTUDO RETROSPECTIVO LONGITUDINAL
}

\begin{abstract}
Dissertação apresentada como requisito parcial para obtenção do Título de Mestre em Ciências da Saúde pelo Programa de Pós-Graduação em Ciências da Saúde da Universidade de Brasília.
\end{abstract}

Aprovado em 27 de fevereiro de 2015.

Profa. Dra. Adriana Lofrano Alves-Porto - (presidente) Universidade de Brasília

Profa. Dra. Ruth Clapauch Universidade Estadual do Rio de Janeiro

Prof. Dr. Augusto César Florêncio Costa Universidade de Brasília

Profa. Dra. Angélica Amorim Amato - (suplente) Universidade de Brasília 
Dedico este trabalho ao meu filho Pedro, por colorir a minha vida com tons nunca antes imaginados. 


\section{AGRADECIMENTOS}

Agradeço ao Pai Maior que de tudo me supriu em Sua infinita misericórdia.

Ao meu marido Maurício, incansável e paciente com os meus anseios e dificuldades, parceiro das minhas aventuras intelectuais.

À minha família, especialmente à minha mãe Viviane e à minha irmã Fernanda, pelo apoio em todos os momentos em que precisei compartilhar a maternidade.

Aos meus mestres da Endocrinologia Pediátrica, Dra. Cátia e Dr. Luiz Cláudio, pelos conhecimentos repassados e pelos exemplos de ética e responsabilidade junto àqueles de quem devemos cuidar.

À minha orientadora Adriana, por fazer brilhar a Ciência em meu coração.

Ao meu parceiro de pesquisa Vitor, que deu vida a este projeto.

Ao grupo de pesquisa, em especial à Olívia, Sara, Cinthia e Petra, que dividiram seus conhecimentos e seu tempo comigo.

Aos professores Luiz Guilherme e Eliane, pelas orientações metodológicas.

Aos queridos pacientes, pela esperança e confiança que depositaram em minha incipiente Medicina. 


\section{RESUMO}

A hiperplasia adrenal congênita constitui um grupo de deficiências genéticas enzimáticas que interfere na síntese normal dos esteróides pelo córtex adrenal. $A$ forma mais comum é a deficiência da 21-hidroxilase que conduz a deficiência de cortisol e produção excessiva de andrógenos adrenais. Suas consequências clínicas são significativas e incluem insuficiência adrenal, genitália ambígua, baixa estatura e infertilidade. Os objetivos do trabalho foram investigar os aspectos clínicos à apresentação, os desfechos clínicos ao longo do seguimento e as associações genótipo-fenótipo dos pacientes portadores de hiperplasia adrenal congênita acompanhados no Hospital Universitário de Brasília. Trata-se de um estudo retrospectivo e longitudinal em que foram levantados os dados clínicos de 29 pacientes com diagnóstico clínico e molecular da deficiência da 21-hidroxilase. Os cálculos estatísticos foram realizados por meio do aplicativo SPSS 20.0 ou STATA 8.2 e a confecção gráfica pelo GraphPadPrism 6. Dos 29 pacientes, 19 eram portadores da forma perdedora de sal e 10 da forma virilizante simples. Houve correlação genótipo-fenótipo em $73,7 \%$ dos perdedores de sal e $70 \%$ dos virilizantes simples. A puberdade precoce central foi mais prevalente nos indivíduos virilizantes simples (66,7\%). A mediana da estatura final foi -1,17 DP no grupo dos perdedores de sal e -2,62 DP no grupo virilizante simples. A dose de hidrocortisona foi significativamente maior nos dois primeiros anos de vida em relação aos anos seguintes de tratamento. Não foi demonstrada associação estatisticamente significativa entre o genótipo e os parâmetros clínicos neste trabalho. Não houve associação entre baixa estatura e puberdade precoce central, e a mediana da dose equivalente de hidrocortisona. Nos pacientes com hiperplasia adrenal congênita forma clássica, observou-se fraca associação entre o genótipo e doses equivalentes de hidrocortisona. Os desfechos clínicos não foram relacionados ao genótipo nem ao tratamento. O tamanho reduzido da amostra pode ter sido um limitante no estudo, porém a variabilidade interindividual quanto às necessidades diárias de glicocorticóide apresenta-se como um desafio adicional no tratamento da hiperplasia adrenal congênita e sugere que fatores genéticos possam modular essa resposta.

Palavras-chave: hiperplasia adrenal; genitália ambígua; insuficiência adrenal. 


\begin{abstract}
Congenital adrenal hyperplasia refers to a group of genetic enzyme deficiencies that impair normal steroid synthesis in the adrenal cortex. The most common form is 21-hydroxylase deficiency, which results in hypocortisolism and androgen overproduction. Important clinical outcomes include adrenal insufficiency, genital ambiguity, short stature and infertility. The aims of the study were to investigate the clinical aspects at presentation, the clinical outcomes and genotypephenotype correlations in patients with congenital adrenal hyperplasia followed at the University Hospital of Brasilia. A retrospective and longitudinal study of 29 patients with clinical and molecular diagnosis of 21-hydroxylase deficiency was performed. Statistics and graphs were evaluated using SPSS 20.0 or STATA 8.2 and GraphPadPrism 6. Nineteen patients had the salt-wasting form and ten had the simple virilizing form. Genotype-phenotype correlation was positive in $73,7 \%$ of the salt-wasting group and $70 \%$ of the simple virilizing group. Central precocious puberty was more prevalent in simple virilizers $(66,7 \%)$. Final height median was -1.17 SD in salt-wasters and -2.62 SD in simple virilizers. Hydrocortisone dose was significantly greater in the first two years than during the following treatment years. There was no association between genotype and clinical features. The median equivalent dose of hydrocortisone was not associated with short stature and central precocious puberty. In the classic form of congenital adrenal hyperplasia, a weak correlation between genotype and treatment was noted. Outcomes were not genotype-related neither treatment-related. A sample-size effect may partially explain the results. However, the interindividual variability in daily glucocorticoid dose requirements remains a challenge in congenital adrenal hyperplasia therapy and suggests that genetic factors could modulate the glucocorticoid response.
\end{abstract}

Key-words: adrenal hyperplasia; genital ambiguity; adrenal insufficiency. 


\section{LISTA DE FIGURAS}

Figura 1. Esteroidogênese.

Figura 2. Exemplo de crossing over desigual durante a meiose entre o gene e o pseudogene.

Figura 3. Correlação genótipo-fenótipo.

Figura 4. Mutações mais comuns do gene CYP21A2.

Figura 5. Classificação de Prader.

Figura 6. Diagnóstico da hiperplasia adrenal após a infância.

Figura 7. Variação entre as médias de dose de hidrocortisona (em $\mathrm{mg} / \mathrm{m}^{2} / \mathrm{dia}$ ) ao longo dos três primeiros anos de vida.

Figura 8. Comparação entre as medianas das dose de hidrocortisona nos dois primeiros anos de vida e nos demais anos de tratamento.

Figura 9. Médias anuais da dose em equivalentes de hidrocortisona nos perdedores de sal ao longo do acompanhamento.

Figura 10. Médias anuais da dose em equivalentes de hidrocortisona nos virilizantes simples ao longo do acompanhamento.

Figura 11. Distribuição da mediana das doses em equivalentes de hidrocortisona ( $m$ HIDROC) de cada paciente. 


\section{LISTA DE TABELAS}

Tabela 1 - As características farmacocinéticas e de potência biológica dos glicocorticóides

Tabela 2 - Características clínicas dos pacientes com hiperplasia adrenal por deficiência da 21-hidroxilase de acordo com a forma clínica

Tabela 3 - Distribuição dos indivíduos conforme a forma clínica da hiperplasia adrenal congênita e grupos de mutações no gene CYP21A2

Tabela 4 - Correlação genótipo-fenótipo conforme os grupos de mutações no gene CYP21A2

Tabela 5 - Desfechos clínicos e doses equivalentes de hidrocortisona ao longo do tratamento em pacientes com hiperplasia adrenal por deficiência da 21-hidroxilase

Tabela 6 - Doses equivalentes de hidrocortisona ao longo do tratamento (mHIDROC) conforme a forma clínica e a ocorrência de baixa estatura e puberdade precoce central em pacientes com a forma clássica de hiperplasia adrenal por deficiência da 21-hidroxilase

Tabela 7 - Análise comparativa entre as doses equivalentes de hidrocortisona ao longo do tratamento (mHIDROC) entre grupos de mutação, ocorrência de baixa estatura e de puberdade precoce central em pacientes com a forma perdedora de sal da hiperplasia adrenal por deficiência da 21-hidroxilase

Tabela 8 - Genótipos 


\section{LISTA DE ABREVIATURAS E SIGLAS}

ACTH - Hormônio adrenocorticotrófico

CRF - fator liberador de corticotropina

CYP21 ou CYP21A2 - gene da 21-hidroxilase

CYP21A1P - pseudogene da 21-hidroxilase

DP - desvio-padrão

EF - estatura final

GH - hormônio de crescimento

GHRH - hormônio liberador do hormônio de crescimento

GnRH - hormônio liberador de gonadotrofina

GR - receptor de glicocorticóide

HAC - hiperplasia adrenal congênita

HLA - complexo principal de histocompatibilidade humana

HUB - Hospital Universitário de Brasília

IGF-1 - fator de crescimento insulina-símile tipo 1

LH - hormônio luteinizante

mHIDROC - mediana das doses equivalentes de hidrocortisona ao longo do tratamento

mHIDROC-i - mediana das doses equivalentes de hidrocortisona ao longo dos 2 anos iniciais de tratamento

mHIDROC-s - mediana das doses de hidrocortisona ao longo dos anos seguintes de tratamento 
PCR - reação em cadeia da polimerase

PPC - puberdade precoce central

PS - perdedor de sal

StAR - proteína reguladora da esteroidogênese aguda

VS - virilizante simples

17OHP - 17-hidroxiprogesterona

21OH - 21-hidroxilase

21OHD - deficiência da 21-hidroxilase 


\section{SUMÁRIO}

1. INTRODUÇÃO 11

1.1 FISIOPATOLOGIA 11

1.2 GENÉTICA MOLECULAR 12

1.3 CORRELAÇÃO GENÓTIPO-FENÓTIPO 13

1.4 APRESENTAÇÃO CLÍNICA 16

$\begin{array}{ll}1.5 \text { TRATAMENTO } & 18\end{array}$

1.6 ACOMPANHAMENTO E COMPLICAÇÕES 19

2. OBJETIVOS 20

2.1 GERAL 20

2.2 ESPECÍFICOS 20

3. MÉTODOS 21

3.1 PACIENTES 21

3.2 ASPECTOS CLÍNICOS - DEFINIÇÕES 22

3.3 DIAGNÓSTICO MOLECULAR 23

3.4 ANÁLISE ESTATÍSTICA $\quad 24$

4. RESULTADOS 25

4.1 CARACTERÍSTICAS CLÍNICAS AO DIAGNÓSTICO 25

4.2 DIAGNÓSTICO MOLECULAR 26

4.3 DESFECHOS AO LONGO DO SEGUIMENTO CLÍNICO: 28

CRESCIMENTO E PUBERDADE 27

4.4 TRATAMENTO 29

4.5 OUTROS DESFECHOS 33

5. DISCUSSÃO 34

6. CONCLUSÃO 40

7. REFERÊNCIAS 42

APÊNDICE $\quad 46$

$\begin{array}{ll}\text { ANEXO } & 57\end{array}$ 


\section{INTRODUÇÃO}

A hiperplasia adrenal congênita (HAC) representa um dos distúrbios geneticamente herdados mais freqüentes da população mundial e está associada à importante morbidade e mortalidade. Constitui um grupo de deficiências genéticas enzimáticas que interfere na síntese normal dos esteróides pelo córtex adrenal. $A$ forma mais comum é a deficiência da 21-hidroxilase $(21 \mathrm{OH})$, correspondendo a cerca de 95\% dos casos. Trata-se de um distúrbio autossômico recessivo que conduz a uma deficiência de cortisol e produção excessiva de andrógenos adrenais por estimulação do hormônio adrenocorticotrópico (ACTH). As conseqüências clínicas da HAC são significativas e incluem insuficiência adrenal, genitália ambígua, baixa estatura, maior risco de síndrome metábolica e infertilidade (1-3).

A incidência varia de 1:10.000 a 1:20.000 nascidos-vivos e é mais prevalente em alguns grupos étnicos, particularmente de regiões remotas (Yupiks do Alasca) (3).

\subsection{FISIOPATOLOGIA}

A produção dos esteróides da adrenal ocorre em três vias principais: glicocorticóides, mineralocorticóides e esteróides sexuais. O ACTH regula a produção dos esteróides por meio de etapas limitantes. Ele permite que a proteína StAR (proteína reguladora da esteroidogênese aguda) realize o transporte do colesterol livre para a membrana interna da mitocôndria, onde ocorre a clivagem da cadeia lateral, marcando o início da esteroidogênese. O sistema nervoso central controla a secreção de ACTH e sua variação diurna via produção do CRF (fator liberador de corticotropina) produzido no hipotálamo. O sistema de retroalimentação hipotálamo-hipófise-adrenal é mediado pelo nível sérico de cortisol, o qual inibe a secreção de CRF e, por conseqüência, de ACTH (2).

A enzima 21-hidroxilase $(210 H)$ realiza a conversão da 17hidroxiprogesterona (17OHP) em 11-deoxicortisol e da progesterona em deoxicorticosterona, precursores do cortisol e da aldosterona, respectivamente. A 
redução da atividade da $210 \mathrm{H}$ com decorrente diminuição da síntese de cortisol resulta em estimulação crônica do córtex adrenal pelo ACTH com hiperplasia adrenal e superprodução dos precursores do cortisol. Esses precursores são desviados para a biossíntese dos andrógenos, que não necessita da atividade da $210 \mathrm{H}$, causando os sinais de virilização $(2,3)$.

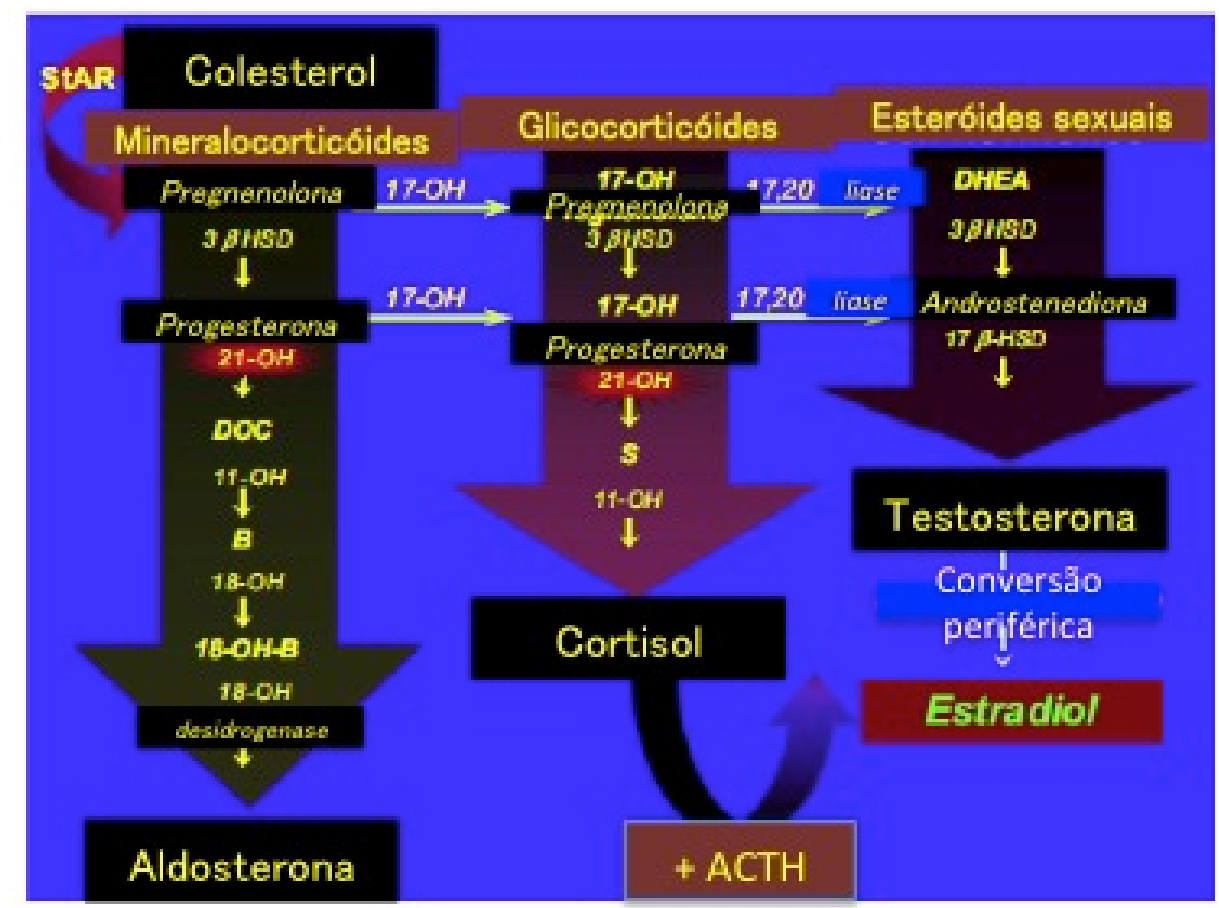

Figura 1. Esteroidogênese. Adaptado de Nimkarn, 2009 (2).

\subsection{GENÉTICA MOLECULAR}

O gene da 21-hidroxilase (CYP21 ou CYP21A2 de acordo com a nova nomenclatura) codifica a enzima tipo II de 495 aminoácidos do citocromo P450. A 21-hidroxilação é mediada por esta enzima mitocondrial específica denominada P450c21; seu gene codificador está localizado no locus do complexo principal de histocompatibilidade humana (HLA classe III) no cromossomo 6p21.3.

Existem dois genes para o P450c21, um pseudogene CYP21A1P e um gene ativo CYP21A2. Ambos contêm 10 éxons e suas seqüências são 98\% idênticas nos éxons e 96\% idênticas nos íntrons. 
O gene CYP21A2 integra uma unidade genética chamada módulo RCCX, formado pelos genes RP, C4, CYP21 e TNX, que se repetem em tandem. O RCCX apresenta três pseudogenes que não produzem proteínas funcionais: CYP21A1P, TNXA e RP2. Assim, em virtude da alta homologia e da organização em tandem, o módulo está sujeito a recombinações gênicas desiguais, que levam a grandes rearranjos incluindo duplicações, conversões, deleções e fusões gênicas $(1,4)$.

A maioria das mutações inativadoras do CYP21A2 são atribuídas a deleções gênicas completas, grandes conversões gênicas, mutações de ponto e deleções 8bp. Devido a sua localização genômica numa região de alta freqüência de recombinações, microconversões ou conversões aparentes, a transferência de material genético do gene CYP21A1P inativo para o gene CYP21A2 ativo é a causa das 8 mais comuns mutações pontuais e deleção 8-bp do éxon $3(1,5)$.

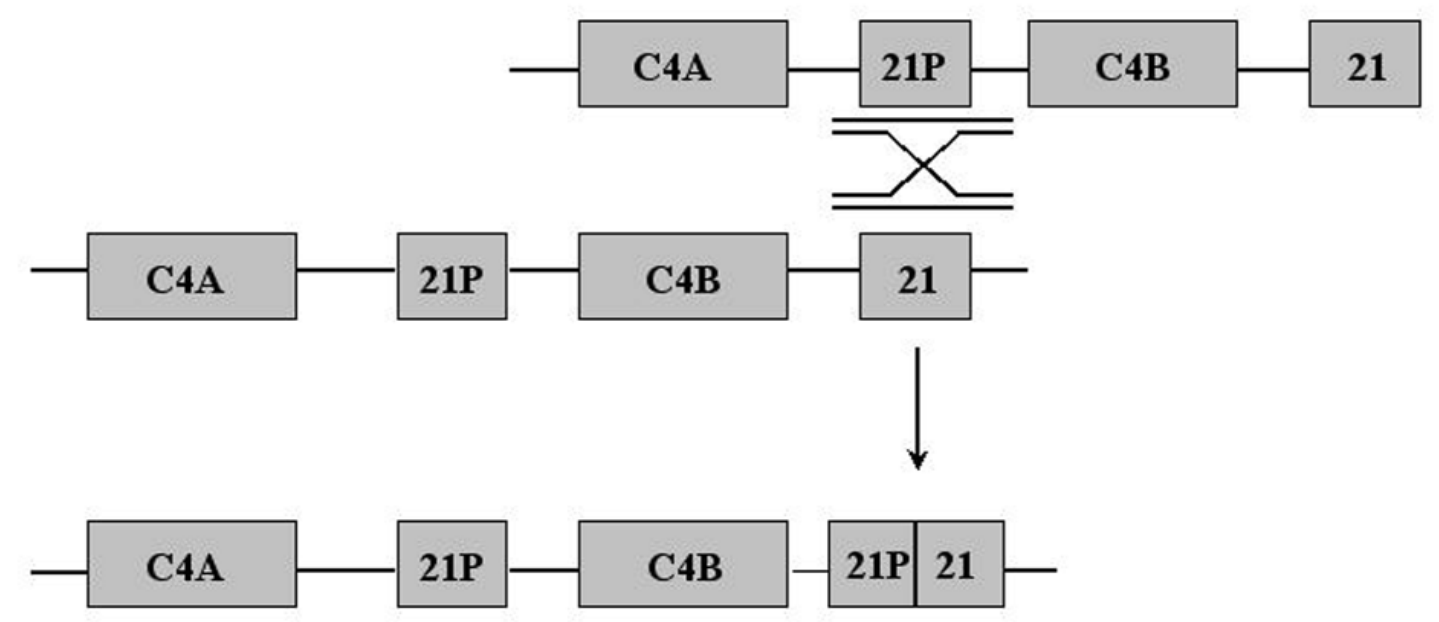

Figura 2. Exemplo de crossing over desigual durante a meiose entre o gene e o pseudogene. Adaptado de Mello, 2002 (5).

\subsection{CORRELAÇÃO GENÓTIPO-FENÓTIPO}

A alta freqüência de pacientes com a HAC por deficiência da $210 \mathrm{H}$ permite correlacionar as diferentes manifestações clínicas da doença com a atividade enzimática conferida por cada mutação observada em estudos de mutagênese e expressão in vitro. 
Speiser e cols. dividiram as mutações em grupos de acordo com 0 comprometimento da atividade enzimática (Figura 3):

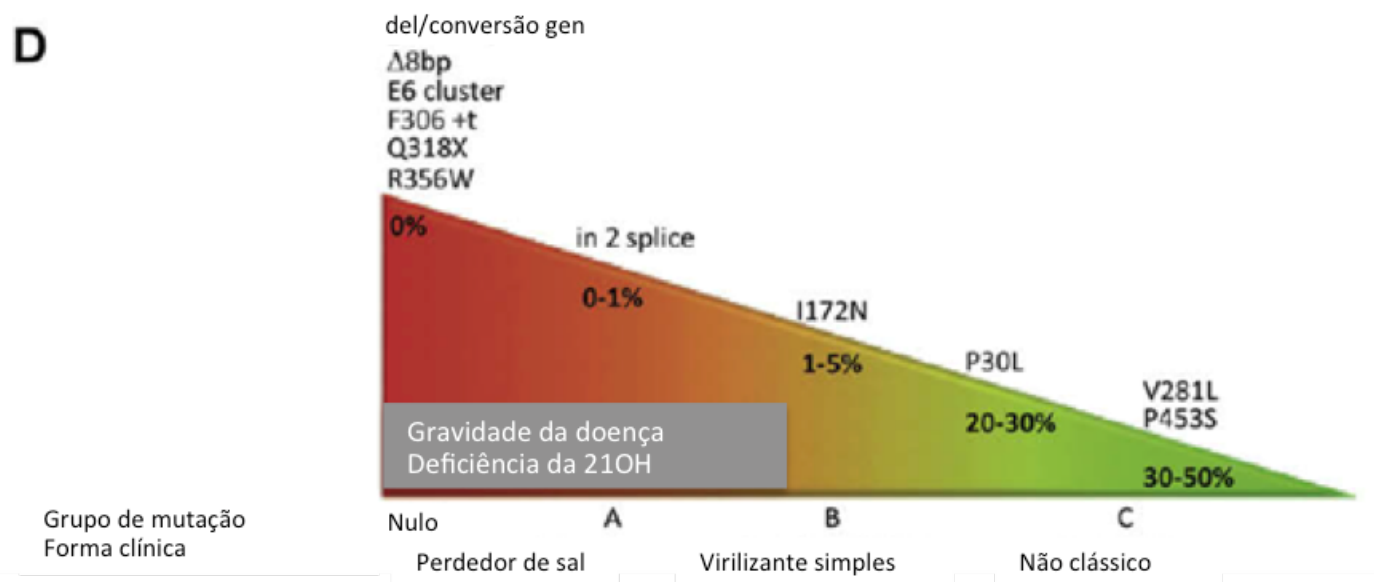

Figura 3. Correlação genótipo-fenótipo. Adaptado de Krone, 2009 (1).

O grupo A incluiu as mutações que abolem a atividade enzimática (subgrupo A1: grandes rearranjos, deleção de 8 nucleotídeos no éxon 3, cluster, Ins T, R356W, Q318X; e subgrupo A2: a mutação 12 splice que confere atividade $<2 \%$ in vitro). $O$ grupo B incluiu a mutação $1172 \mathrm{~N}$ que confere 3 a $7 \%$ de atividade enzimática. $\mathrm{O}$ grupo C incluiu as mutações V281L e P30L, que conferem mais que $20 \%$ de atividade enzimática.

Os autores observaram que indivíduos homozigotos para mutações do grupo A apresentaram principalmente a forma perdedora de sal, homozigotos para a mutação do grupo B ou em heterozigose composta com as mutações do grupo $A$ apresentaram a forma virilizante simples, e os homozigotos para mutações do grupo C ou em heterozigose composta com as anteriores apresentaram a forma não clássica. Foi visto que a forma clínica em um indivíduo heterozigoto composto, isto é, mutações diferentes entre os alelos, é definida pelo alelo que apresenta maior atividade enzimática $(1,5)$.

A análise do genótipo da deficiência da $210 \mathrm{H}$ na população brasileira foi realizada por Bachega et al num estudo multicêntrico. Notou-se que as mutações mais freqüentes foram 12 splice, I172N e V281L e estiveram associadas significativamente com as formas perdedora de sal, virilizante simples e não clássica respectivamente. As deleções apresentaram baixa freqüência, de forma semelhante ao encontrado na população argentina e mexicana. Cinco mutações novas foram 
relatadas: G424S, H28+C, Ins 1003^1004 A, R408C e IVS2-2A>G.6. Como a nossa população apresenta alto grau de miscigenação, é provável que estas sejam identificadas também em outras populações. Estudos de seqüenciamento identificaram mutações em $100 \%$ dos alelos da forma clássica, enquanto que a forma não clássica permanece ainda com freqüência alta de alelos sem mutações identificadas.

No estudo de Bachega et al, as mutações mais freqüentes na população brasileira com deficiência da 21-hidroxilase são também as derivadas do pseudogene CYP21A1P, podendo ser pesquisadas por técnicas como o PCR aleloespecífico. A mutação 12 splice, a mais freqüente, foi associada principalmente à forma perdedora de sal, mas também à forma virilizante simples (6).

Uma pesquisa mais recente avaliou a relação genótipo-fenótipo em 1507 famílias portadoras de HAC por deficiência da $210 \mathrm{H}$ e encontraram uma correlação positiva em 21 dos 45 genótipos. Os autores relatam que algumas mutações como a P30L, I2G e I172N apresentaram fenótipos variáveis. Ademais, acreditam que a gravidade da doença pode ser, em geral, predita nos genótipos para perdedores de sal e forma não clássica, ao contrário da forma virilizante simples, onde há grande variabilidade fenotípica (7). Na Figura 4 são apresentadas as principais mutações e sua localização:

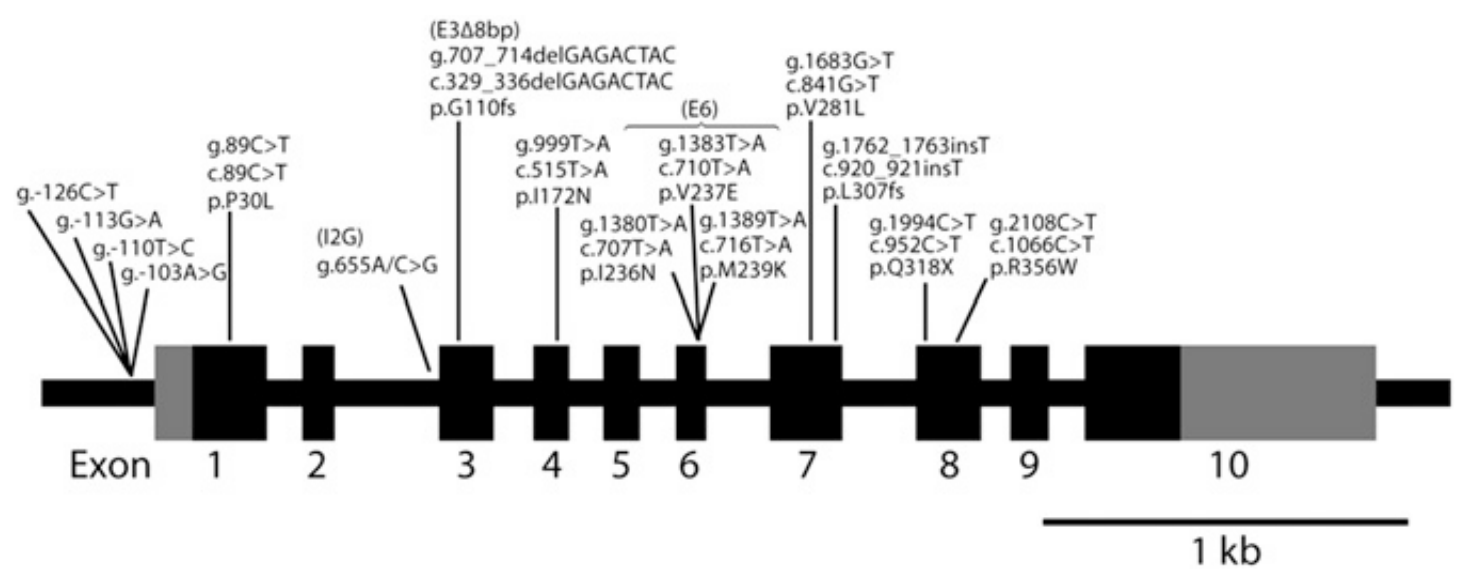

Figura 4. Mutações mais comuns do gene CYP21A2. Adaptado de New, 2013 (7). 


\subsection{APRESENTAÇÃO CLÍNICA}

A HAC por deficiência da $210 H$ é dividida em forma clássica e não-clássica.

Na forma clássica, a exposição androgênica pré-natal provoca a virilização e ambigüidade da genitália externa nos recém-nascidos femininos e virilização pósnatal progressiva em ambos os sexos.

As pacientes afetadas com a forma clássica apresentam sintomas mais graves de hiperandrogenismo. Além disso, três-quartos desses pacientes evoluem com a síndrome perdedora de sal em virtude da deficiência de aldosterona, levando a quadros de desidratação e óbito. Por outro lado, os outros $25 \%$ apresentam a forma virilizante simples caracterizada por virilização pós-natal da genitália externa no sexo feminino e aparecimento precoce de caracteres sexuais secundários; ambos os fatos decorrentes do aumento da produção de andrógenos.

$\mathrm{Na}$ forma não clássica os sintomas se iniciam mais tardiamente com quadro de pubarca precoce, alterações menstruais, hirsutismo, infertilidade ou pode ser assintomática.

Estas diferentes formas clínicas surgem pelo amplo espectro do comprometimento da atividade da 21-hidroxilase, causado por mutações no gene que codifica a enzima conforme já apresentado acima $(2,3)$.

O córtex adrenal é formado na quarta semana de gestação a partir do mesoderma epitelial celômico. Em torno da sexta ou sétima semana, o córtex adrenal funcional começa a secretar esteróides. O momento crítico para a diferenciação sexual da genitália externa ocorre entre 7 a 12 semanas. Durante esse período, a exposição excessiva do feto feminino 46,XX aos andrógenos adrenais ocasiona a masculinização da genitália ao nascimento. Nos fetos afetados, os precursores da via da esteroidogênese são redirecionados para a via de produção dos andrógenos.

Os graus de virilização genital no sexo feminino variam: aumento do clitóris, fusão das eminências labiais e migração rostral da uretra/orifício vaginal. Entretanto, a genitália interna (útero, tubas uterinas e ovários) é normal visto que as mulheres afetadas não podem produzir o fator inibidor mülleriano na ausência de testículos. Como os ductos müllerianos não regridem, a genitália interna pode se desenvolver normalmente. Dessa maneira, as mulheres com a doença são férteis (8). 
A masculinização da genitália externa é classificada segundo os estágios de Prader (Figura 5).

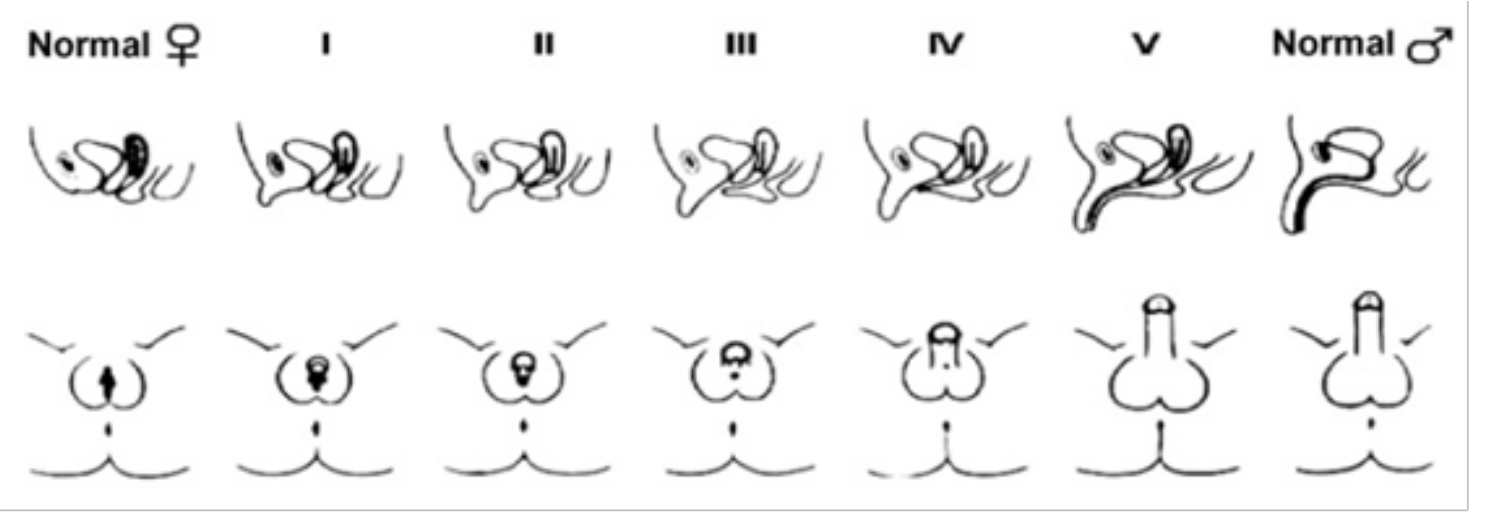

Figura 5. Classificação de Prader. Adaptado de Nimkarn, 2008 (8).

- Estágio I: clitoromegalia sem fusão labial

- Estágio II: clitoromegalia e fusão labial posterior

- Estágio III: clitoromegalia acentuada, orifício urogenital perineal único e fusão labial quase completa

- Estágio IV: grande aumento fálico do clitóris, uretra semelhante a seio urogenital na base do clitóris e fusão labial completa

- Estágio V: clitóris peniano, meato uretral na extremidade do falo e eminências labiais semelhantes à bolsa escrotal (semelhante a genitália masculina sem gônadas palpáveis) (8).

O diagnóstico pela triagem neonatal permite identificar meninos e meninas afetados, previne o registro incorreto do gênero e diminui a morbidade e mortalidade decorrentes da HAC, sendo globalmente recomendada. O exame em papel filtro deve ser realizado entre 48-72 horas do nascimento e detecta alterações no nível de $17 \mathrm{OH}$-progesterona cujos valores devem ser padronizados localmente pelo laboratório. O diagnóstico necessita ser posteriormente confirmado por meio de dosagem sérica da 170HP (9).

A recomendação atual para o diagnóstico pós-natal é a realização da dosagem sérica matinal de 170HP em indivíduos sintomáticos ou um perfil adrenal completo após teste de estímulo com ACTH naqueles casos duvidosos ou naqueles 
em que é preciso diferenciar a deficiência de $210 \mathrm{H}$ de outros defeitos da esteroidogênese (Figura 6) (3).

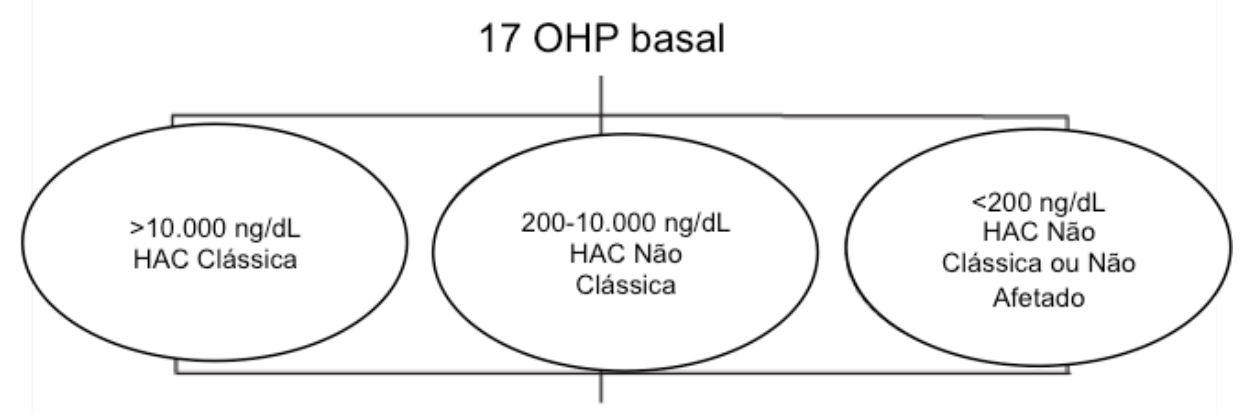

17 OHP pós-ACTH

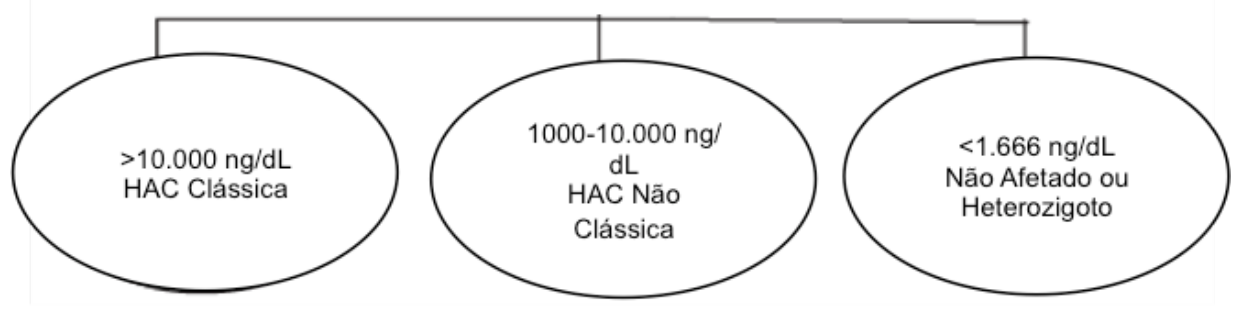

Figura 6. Diagnóstico da hiperplasia adrenal após a infância. Adaptado de Speiser, 2010 (3).

\subsection{TRATAMENTO}

O objetivo do tratamento da HAC é substituir os esteróides deficientes e minimizar o excesso de esteróides sexuais no sentido de impedir a virilização, melhorar o crescimento e a fertilidade.

A hidrocortisona é a droga de primeira escolha na infância na forma de comprimidos. Doses excessivas levam à supressão do crescimento, à obesidade, ao hipercortisolismo exógeno.

Os glicocorticóides de ação prolongada podem ser uma opção após o fechamento das epífises como a prednisolona, prednisona e dexametasona.

Todas as crianças devem receber a fludrocortisona quando o diagnóstico é feito no período neonatal. O uso do mineralocorticóide permite uma menor dose de glicocorticóide. A necessidade de manutenção da fludrocortisona deve ser avaliada 
baseada na atividade de renina plasmática e na pressão arterial. O cloreto de sódio na dose de 1-3g/dia deve ser oferecido em várias tomadas ao longo do dia (9).

\subsection{ACOMPANHAMENTO E COMPLICAÇÕES}

O manejo dos pacientes portadores de HAC é dinâmico, pois se modifica ao longo da vida. Na infância, o foco é atingir um crescimento e desenvolvimento normal, enquanto no adulto é desejável prevenir as complicações de longo prazo como obesidade, osteoporose e síndrome metabólica (10).

A maior parte das coortes que acompanham esses pacientes demonstra a dificuldade de atingir um bom controle metabólico com o uso dos regimes terapêuticos atuais. Entretanto, os pesquisadores afirmam que os desfechos clínicos não estão associados ao genótipo; ao contrário, o estado de saúde desses pacientes é adquirido e, portanto, pode ser melhorado (11). 


\section{OBJETIVOS}

\subsection{GERAL}

Investigar as características clínicas à apresentação, desfechos clínicos ao longo do seguimento e associações genótipo-fenótipo de uma série de indivíduos com diagnóstico da forma clássica de hiperplasia adrenal congênita por deficiência da 21-hidroxilase, acompanhados nos ambulatórios de Endocrinologia das Gônadas e Adrenais e Endocrinologia Pediátrica do HUB-UnB entre 2000 e 2013.

\subsection{ESPECÍFICOS}

-Investigar os aspectos clínicos de indivíduos com hiperplasia adrenal congênita por deficiência da 21-hidroxilase acompanhados nos ambulatórios de Endocrinologia do HUB, ao diagnóstico e ao longo do seguimento, a saber: a) idade ao diagnóstico; b) gênero; c) forma clínica; d) concentrações de 170HP plasmática ao diagnóstico; e) idade da pubarca e menarca; f) freqüência de puberdade precoce central; g) estatura final; h) tipo de glicocorticóide e doses equivalentes de hidrocortisona utilizadas ao longo do tratamento.

-Analisar a correlação do genótipo da CYP21A2 com o fenótipo da deficiência de 21-hidroxilase (revisado de Araújo, 2013 [12]).

-Investigar as associações entre os aspectos clínicos ao diagnóstico (idade, gênero, forma clínica, 17OHP plasmática), desfechos ao longo do seguimento (idade da pubarca e/ou menarca, puberdade precoce central e estatura final), doses de glicocorticóide e genótipo desses indivíduos. 


\section{MÉTODOS}

\subsection{PACIENTES}

A partir dos registros existentes nas agendas dos ambulatórios de Endocrinologia Pediátrica e Gônadas e Adrenais do HUB, entre 2000 e 2013, foram identificados os pacientes em que constava o diagnóstico de hiperplasia adrenal congênita por deficiência da 21-hidroxilase. Dentre eles, foram selecionados os que compareceram às consultas regulares no período do estudo e/ou que responderam a contato telefônico, e cujo diagnóstico havia sido confirmado por critérios clínicos e hormonais, a saber: virilização da genitália externa em neonatos do sexo feminino, virilização pós-natal em ambos os sexos, perda de sal e/ou teste positivo na triagem neonatal para HAC associados a dosagem anormal de 17OHP plasmática.

Foram excluídos os que perderam o seguimento, os que não tinham resultado de teste genético ou que se recusaram a participar do estudo.

Os dados clínicos foram obtidos por meio de revisão de prontuários no período de janeiro de 2012 à julho de 2013. A ficha clínica elaborada para tal fim está no APÊNDICE A.

O diagnóstico clínico foi confirmado pelo genótipo. Os testes genéticos foram realizados em estudo paralelo apresentado na dissertação de Araújo, 2013 (12).

A classificação da forma clínica foi feita por meio das características clínicas e laboratoriais $(2,9)$ e houve reclassificação em alguns casos, de acordo com o genótipo obtido.

A pesquisa foi aprovada pelo Comitê de Ética da Faculdade de Ciências da Saúde da Universidade de Brasília (registro 112/11) conforme apresentado no ANEXO A. O termo de consentimento livre e esclarecido foi entregue e assinado pelos pacientes ou responsáveis e pelos pesquisadores (APÊNDICE B). 


\subsection{ASPECTOS CLÍNICOS - DEFINIÇÕES}

Os pacientes foram divididos conforme a forma clínica: perdedora de sal ou virilizante simples.

A concentração plasmática de 17-hidroxiprogesterona foi utilizada como critério diagnóstico. Entretanto, observou-se que, na maioria dos casos, os pacientes já estavam em vigência de corticoterapia no momento da primeira dosagem. Dessa forma, entende-se que os valores estavam falsamente reduzidos ao diagnóstico.

Os dados de pubarca e menarca foram extraídos dos prontuários conforme relatados no exame físico ou anamnese. Para fins de análise, foram incluídos apenas os pacientes que já haviam iniciado a puberdade.

Optou-se por não incluir a avaliação da gonadarca nos indivíduos do gênero masculino, uma vez que os dados de volume testicular podem variar conforme o examinador e o estudo em questão foi retrospectivo.

Os critérios utilizados para o diagnóstico de puberdade precoce central (PPC) foram: a) aparecimento de caracteres sexuais secundários em meninas antes dos 8 anos e em meninos antes dos 9 anos; b) LH (hormônio luteinizante) plasmático basal acima de 0,6U/L em ambos os sexos pelo método imunofluorimétrico ou $0,2 U / L$ pelo método de quimioluminescência; c) avanço de idade óssea e perda de estatura final $(14,15)$. A freqüência de PPC foi determinada considerando o número de pacientes que já haviam concluído a puberdade e/ou que estavam em vigência de tratamento com análogo de $\mathrm{GnRH}$ (hormônio liberador de gonadotrofinas).

A estatura final foi avaliada por meio de cálculo do escore-z da curva de crescimento da Organização Mundial de Saúde de 2006-2007 e expressa em desvios-padrão (DP). A freqüência de indivíduos com baixa estatura foi determinada considerando o número de pacientes que já haviam concluído o crescimento, ou seja, que atingiram 15 a 16 anos de idade óssea para meninas e 17 a 18 anos de idade óssea para meninos. A baixa estatura foi definida quando, ao término do crescimento, o paciente apresentava estatura final abaixo de -2 desvios-padrão $(16,17)$. 
As doses e tipos de glicocorticóide em uso nas consultas foram registrados e convertidos em equivalentes de hidrocortisona de acordo com sua potência biológica (Tabela 1)(18, 19).

\begin{tabular}{|c|c|c|c|c|c|}
\hline Droga & Potência & $\begin{array}{c}\text { Dose } \\
\text { equivalente }(\mathrm{mg})\end{array}$ & $\begin{array}{c}\text { Retenção } \\
\text { de Na }\end{array}$ & $\begin{array}{c}\text { 1/2 vida } \\
\text { plasma (min) }\end{array}$ & $\begin{array}{l}1 / 2 \text { vida } \\
\text { biológica }\end{array}$ \\
\hline Hidrocortisona (cortisol) & 1 & 20 & 1 & 90 & 8-12 \\
\hline Acetato de cortisona & 0,8 & 25 & 0,8 & 30 & $8-12$ \\
\hline Prednisona & 4 & 5 & 0,2 & 60 & $12-36$ \\
\hline Prednisolona & 5 & 4 & 0,2 & 200 & $12-36$ \\
\hline Metil-Prednisolona & 5 & 4 & 0 & 180 & $12-36$ \\
\hline Triamcinolona & 5 & 4 & 0 & 300 & $24-72$ \\
\hline Dexametasona & 2 & 0,75 & 0 & 300 & $24-72$ \\
\hline Betametasona & 2 & 0,5 & 0 & 300 & $24-72$ \\
\hline
\end{tabular}

Tabela 1. As características farmacocinéticas e a potência biológica dos glicocorticóides. Adaptado de Romanholi, 2007 (18).

A dose média de hidrocortisona anual para cada paciente foi utilizada como indicador da carga total de glicocorticóide para cada paciente ao longo do seu respectivo tempo de seguimento, a qual foi expressa como a mediana das doses de hidrocortisona (mHIDROC) (APÊNDICE C). Foram consideradas elevadas mHIDROC superiores a $15 \mathrm{mg} / \mathrm{m}^{2} / \mathrm{dia}(3)$.

Quando indicado, os dados clínicos foram categorizados e as freqüências de PPC e baixa estatura em cada grupo foram analisadas.

\subsection{DIAGNÓSTICO MOLECULAR}

O estudo molecular dos indivíduos incluídos no presente estudo foi realizado previamente (12) e o detalhamento do genótipo de cada paciente encontra-se no ANEXO B.

Para análise e investigação das associações do genótipo da CYP21A2 com os aspectos clínicos, os pacientes foram divididos em dois grupos. O grupo 1 corresponde àqueles que apresentaram pelo menos uma mutação que se associa à atividade enzimática nula ou de até 1\% (grupos nulo e A da classificação de Speiser). O grupo 2 compreende os casos em que as mutações encontradas resultam em perda moderada da atividade enzimática (grupos B e C da classificação de Speiser) (1). 


\subsection{ANÁLISE ESTATÍSTICA}

Para a análise da distribuição das variáveis contínuas (idade ao diagnóstico, nível sérico de 17-hidroxiprogesterona, idade da pubarca, idade da menarca, escorez de estatura final e dose de hidrocortisona) foi aplicado o teste de Shapiro-Wilk. Diante do padrão de distribuição não paramétrica observado, os dados foram expressos como mediana e extremos (valores mínimo e máximo).

Nas análises inferenciais, as variáveis contínuas foram comparadas entre e nos grupos de interesse por meio de testes não paramétricos, Kruskal-Wallis ou Mann-Whitney, como indicado. As variáveis categorizadas foram comparadas entre e nos grupos de interesse por meio de $X^{2}$ ou teste exato de Fisher. A correlação de Spearman foi aplicada para análise de associações entre variáveis contínuas.

A análise da comparação das proporções e correlações foi considerada estatisticamente significativa quando as probabilidades das suas ocorrências devidas ao acaso (erro tipo I) foram menores ou iguais a $5 \%(p \leq 0,05)$. Os cálculos estatísticos foram realizados por meio do aplicativo SPSS 20.0 ou STATA 8.2 e a confecção gráfica pelo GraphPadPrism 6. 


\section{RESULTADOS}

\subsection{CARACTERÍSTICAS CLÍNICAS AO DIAGNÓSTICO}

Foram identificados 43 indivíduos com o diagnóstico de HAC por deficiência da 21-hidroxilase forma clássica nos registros de prontuários disponíveis. Dentre eles, 29 pacientes foram incluídos no estudo. Onze pacientes foram excluídos por terem perdido o seguimento, dois pacientes por não ter sido possível obter o genótipo e um paciente recusou-se a participar.

Quatro pacientes foram diagnosticados pelo Programa de Triagem Neonatal da Secretaria de Saúde do Distrito Federal, o qual foi instituído em 2012. O programa segue as diretrizes do Ministério da Saúde (13). Os demais 25 pacientes foram diagnosticados antes de 2012 e, portanto, foram utilizados critérios clínicos e hormonais compatíveis com a doença $(2,3,9)$.

Nos casos em que o diagnóstico e o acompanhamento no HUB foi iniciado antes do ano de 2000 nos ambulatórios de Endocrinologia Geral ou Pediatria, as características clínicas relevantes foram consideradas.

Quanto à forma clínica, os pacientes incluídos foram classificados inicialmente de acordo com a apresentação clínica ao diagnóstico e confirmados ou reclassificados posteriormente conforme o genótipo. Todos os indivíduos incluídos eram portadores da forma clássica da doença, sendo 19 perdedores de sal e 10 virilizantes simples.

No grupo de perdedores de sal, 68,4\% eram do gênero masculino. No grupo de indivíduos da forma virilizante simples, 80\% eram do gênero feminino.

A mediana da idade ao diagnóstico foi de 1 mês de vida no grupo de perdedores de sal. Um indivíduo teve diagnóstico referido aos 25 meses de vida, contudo. Nesse grupo, a mediana da concentração plasmática de 17 hidroxiprogesterona foi de $5250 \mathrm{ng} / \mathrm{dL}$, variando de 1058 a $256.000 \mathrm{ng} / \mathrm{dL}$. Já no grupo de virilizantes simples, a mediana da idade ao diagnóstico foi de 49 meses, isto é, 4 anos e 1 mês, variando entre 10 meses e 13 anos. Nesse grupo, a mediana da 17 hidroxiprogesterona foi de 2375 ng/dL (704 a 56.200 ng/dL) (Tabela 2). 
Tabela 2 - Características clínicas dos pacientes com hiperplasia adrenal por deficiência da 21-hidroxilase de acordo com a forma clínica

\begin{tabular}{|c|c|c|}
\hline & \multicolumn{2}{|c|}{ Forma clínica } \\
\hline & Perdedor de Sal & Virilizante Simples \\
\hline Número de indivíduos (n) & 19 & 10 \\
\hline \multicolumn{3}{|l|}{ Gênero } \\
\hline Masculino, n (\%) & $13(68,4 \%)$ & $2(20 \%)$ \\
\hline Feminino, n (\%) & $6(31,6 \%)$ & $8(80 \%)$ \\
\hline Idade ao diagnóstico* (meses) & $1(0 / 25)$ & $49(10$ / 156) \\
\hline $17 \mathrm{OHP}{ }^{* 1}(\mathrm{ng} / \mathrm{dL})$ & 5250 (1058 / 256000) & 2375 (704 / 56200) \\
\hline
\end{tabular}

\subsection{DIAGNÓSTICO MOLECULAR}

Os pacientes foram separados em dois grupos de mutação conforme apresentado anteriormente. O grupo 1 corresponde aos grupos nulo e A da classificação de Speiser e, o grupo 2, aos grupos B e C da mesma classificação. Optou-se por essa forma de reagrupamento com o intuito de separar as mutações graves, que cursam com perda importante da função da enzima (0 a $1 \%$ de atividade), das mutações menos graves, com função enzimática residual (30 a 50\% de atividade), considerando que a amostra estudada era constituída apenas de indivíduos com a forma clássica da doença. Além disso, esse agrupamento possibilitou análises comparativas e de associação entre os dados clínicos e os genótipos.

Dentre os pacientes perdedores de sal $(n=19), 73,7 \%$ apresentaram um genótipo mais grave e, portanto, foram reunidos no grupo 1 , enquanto $26,3 \%$ constituíram o grupo 2. Já em relação aos pacientes com a forma virilizante simples $(n=10), 40 \%$ apresentaram o genótipo correspondente ao grupo 1 e $60 \%$ ao grupo 2 .

A taxa de correlação genótipo-fenótipo foi semelhante, independentemente da forma clínica $(73,7 \%$ e $70 \%$, entre perdedores de sal e virilizantes simples, respectivamente). Adicionalmente, na análise inferencial, não se observou 
associação da forma clínica da doença com o grupo de mutação $(p=0,11)$ (Tabela 3).

Tabela 3 - Distribuição dos indivíduos conforme a forma clínica da hiperplasia adrenal congênita e grupos de mutações no gene CYP21A2

\begin{tabular}{ccc}
\hline \multicolumn{2}{c}{ Forma clínica } & $p^{*}$ \\
\hline Perdedor de Sal & Virilizante Simples
\end{tabular}

Genótipo $^{1}$

$\begin{array}{lccc}\text { Grupo 1, n (\%) } & 14(73,7 \%) & 4(40 \%) & 0,11 \\ \text { Grupo 2, n (\%) } & 5(26,3 \%) & 6(60 \%) & \end{array}$

* Valor $p$ obtido pelo teste exato de Fisher

1 Genótipos:

Grupo 1: corresponde aos grupos nulo e A da classificação de Speiser (mutações com perda funcional grave)

Grupo 2: corresponde aos grupos B e C da classificação de Speiser (mutações com perda funcional moderada)

No entanto, os pacientes com mutações mais graves (grupo 1 - $n=14$ ) apresentaram melhor correlação genótipo-fenótipo $(p=0,03)$ (Tabela 4).

Tabela 4 - Correlação genótipo-fenótipo conforme os grupos de mutações no gene CYP21A2

\begin{tabular}{lccc}
\hline & \multicolumn{2}{c}{ Correlação genótipo-fenótipo } & $p^{*}$ \\
\hline Genótipo ${ }^{1}$ & + & - & \\
& & & \\
Grupo 1, n (\%) & $16(88,9 \%)$ & $2(11,1 \%)$ & 0,03 \\
Grupo 2, n (\%) & $5(45,5 \%)$ & $6(54,5 \%)$ & \\
\hline
\end{tabular}

* Valor $p$ obtido pelo teste exato de Fisher

1 Genótipos:

Grupo 1: corresponde aos grupos nulo e A da classificação de Speiser (mutações com perda funcional grave)

Grupo 2: corresponde aos grupos B e C da classificação de Speiser (mutações com perda funcional moderada)

Um paciente com diagnóstico tardio e sem informações dos primeiros anos de vida, por ser adotivo, foi reclassificado como perdedor de sal após análise molecular (ANEXO B). 


\subsection{DESFECHOS AO LONGO DO SEGUIMENTO CLÍNICO: CRESCIMENTO E PUBERDADE}

A mediana da idade da pubarca nos perdedores de sal foi 5,5 anos enquanto que no grupo dos virilizante simples foi 4,3 anos. Em relação à menarca, constatouse 10,9 anos nos perdedores de sal e 11,3 anos nos virilizantes simples (Tabela 5).

A puberdade precoce central foi mais prevalente nos indivíduos virilizantes simples $(66,7 \%)$ (Tabela 5). A freqüência foi calculada sobre o número de pacientes que já haviam concluído a puberdade e/ou que estavam em vigência de tratamento. Nesse caso, apenas 12 pacientes do grupo perdedor de sal e 6 do grupo virilizante simples. O tratamento utilizado para todos os pacientes foi o análogo de $\mathrm{GnRH}$ (hormônio liberador de gonadotropina) triptorrelina 3,75 mg por via intramuscular em aplicações mensais. Entretanto, em 3 pacientes optou-se por não realizar o bloqueio puberal pelo grande avanço de idade óssea.

A mediana da estatura final foi considerada normal no grupo dos perdedores de sal (-1,17 DP), mas abaixo de 2 desvios-padrão no grupo virilizante simples (2,62 DP). Ademais, constatou-se que a baixa estatura esteve presente em todos os virilizantes simples, diferentemente do grupo de perdedores de sal (27,3\%). Para o cálculo de frequência, foram incluídos os pacientes que já haviam concluído o crescimento: 11 do grupo perdedor de sal e 5 do grupo virilizante simples (Tabela 5).

Não foi encontrada associação estatisticamente significativa do genótipo com a baixa estatura $(p=1)$ ou com a puberdade precoce $(p=1)$. Todavia, a baixa estatura foi associada ao fenótipo virilizante simples $(p=0,03)$. A presença de puberdade precoce central não demonstrou associação com a forma clínica $(p=0,14)$. 
Tabela 5 - Desfechos clínicos e doses equivalentes de hidrocortisona ao longo do tratamento em pacientes com hiperplasia adrenal por deficiência da 21-hidroxilase

Forma clínica

Perdedor de Sal Virilizante Simples

Idade da pubarca (anos) ${ }^{1}$

$\mathrm{n}$

12

8

mediana (mín / máx)

$5,5(2 / 11,5)$

$4,3(0,3 / 6,1)$

Idade da menarca (anos) ${ }^{2}$

$\mathrm{n}$

5

6

mediana (mín / máx)

$10,9(8,7 / 13,2)$

11,3 (9,5 / 19)

$\mathrm{PPC}^{3}$

n (\%)

$3(25 \%)$

$4(66,7 \%)$

Escore-z de EF (DP) ${ }^{4 \#}$

mediana (mín / máx)

$-1,17(-4,55 /-0,07)$

$-2,62(-3,46 /-2,09)$

Baixa estatura ${ }^{5 \#}$

n (\%)

$3(27,3 \%)$

$5(100 \%)$

mHIDROC $\left(e m ~ m g / m^{2} / d i a\right)^{6}$

mediana (mín / máx)

$16,5(7,01 / 28,82)$

$13,78(9,01 / 32,67)$

1 Incluídos somente os pacientes que já haviam iniciado a puberdade

2 Incluídas as pacientes que já haviam apresentado a menarca e/ou em término de puberdade

3 Puberdade precoce central (freqüência calculada sobre o número de pacientes que já haviam concluído a puberdade e/ou em vigência de tratamento com análogo de $\mathrm{GnRH}$ )

4 Escore de estatura final em desvios-padrão

5 Definida como uma estatura final abaixo de -2 desvios-padrão

6 Mediana das doses de glicocorticóide utilizadas ao longo do tratamento, convertidas em equivalentes de hidrocortisona

\# A referência é a curva de crescimento da Organização Mundial de Saúde (OMS) de 2006-2007. A freqüência foi calculada sobre o número de pacientes que já haviam concluído o crescimento.

\subsection{TRATAMENTO}

Vinte e quatro pacientes receberam glicocorticóide na forma de hidrocortisona suspensão, 17 como prednisolona suspensão e 17 como dexametasona suspensão ou comprimido. Vinte pacientes receberam diferentes esquemas ao longo do acompanhamento. 
A mediana da dose de hidrocortisona de acordo com a forma clínica foi apresentada na Tabela 5. A dose média anual ao longo do tempo para cada paciente e a mediana das doses em equivalentes de hidrocortisona para cada paciente está no APÊNDICE C.

Inicialmente, buscou-se observar o padrão de distribuição das doses equivalentes de hidrocortisona utilizadas nos primeiros anos de tratamento, em comparação aos anos seguintes. Considerando o risco e a gravidade da crise adrenal em lactentes, é bem conhecida a necessidade de doses maiores de glicocorticóide nos primeiros anos de tratamento. Assim, para essa análise, só os perdedores de sal foram incluídos, por terem seu diagnóstico estabelecido precocemente.

Assim, avaliou-se a variação percentual entre as médias de dose de hidrocortisona nos três primeiros anos de vida dos perdedores de sal (Figura 7). A redução do início para o término do primeiro ano de tratamento foi de $-17,8 \%$ ($63,9 \%$ a179,3\%); de $-9,7 \%$ (-66,3\% a 265,2\%) do primeiro para o segundo ano; e houve um aumento ao final do terceiro ano de $16,6 \%(-26,7 \%$ a $56,3 \%)$. As diferenças não foram estatisticamente significativas $(p=0,1)$.

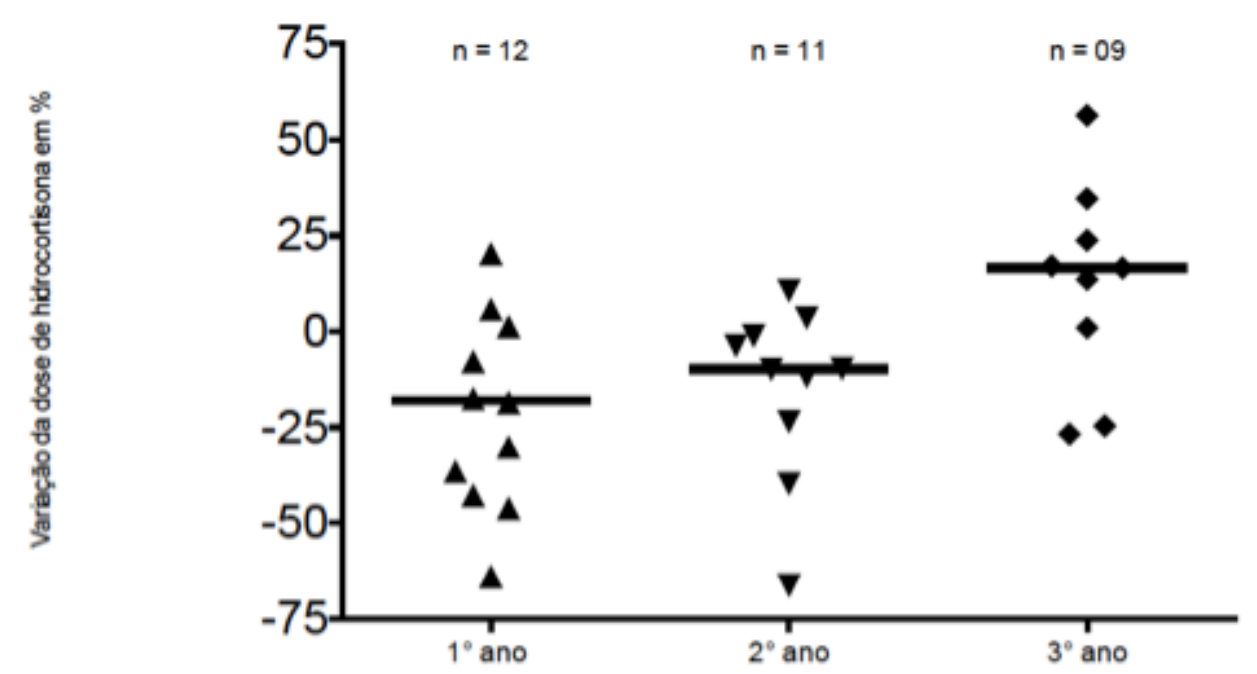

Figura 7. Variação entre as médias de dose de hidrocortisona (em mg/m²/dia) ao longo dos três primeiros anos de vida ( $p=0,1$ obtido pelo teste de Kruskal-Wallis).

A mediana das doses anuais de hidrocortisona dos dois primeiros anos de vida dos pacientes perdedores de sal foi comparada aos demais anos de tratamento. A diferença foi estatisticamente significativa $(p<0,0001)$. Nos dois primeiros anos de 
tratamento a mediana foi de $35,6 \mathrm{mg} / \mathrm{m}^{2} / \mathrm{dia}$ (variou de 20,5 a 70 ) e nos demais anos de $16,2 \mathrm{mg} / \mathrm{m}^{2} / \mathrm{dia}$ (variou de 6,5 a 28,28) (Figura 8).

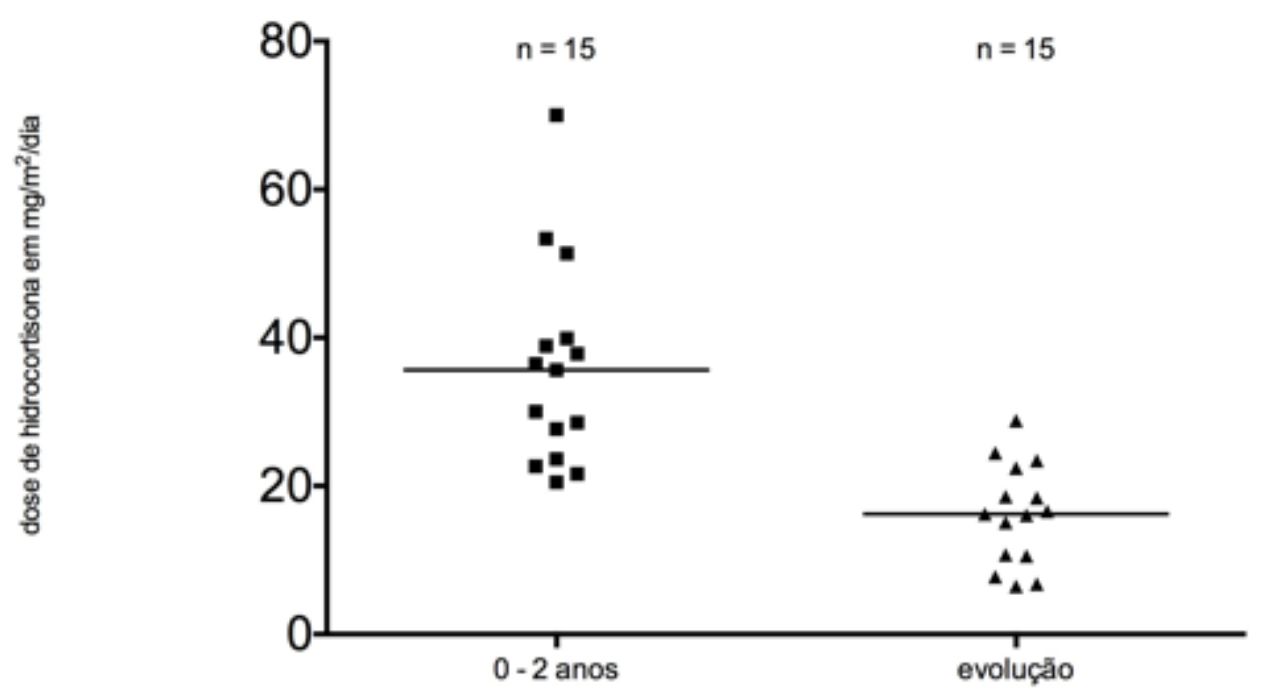

Figura 8. Comparação entre as medianas das doses de hidrocortisona nos dois primeiros anos de vida e nos demais anos de tratamento $(p<0,0001$ obtido pelo teste de Mann-Whitney).

Foram analisadas as possíveis associações entre a necessidade de glicocorticóide ao longo da vida e o genótipo, forma de apresentação da doença e desfechos clínicos relacionados a crescimento e puberdade.

A dose de hidrocortisona não variou entre os grupos de mutação $(p=0,62)$ nem entre as formas clínicas $(p=0,52)$. Quando avaliado o impacto da dose nos desfechos clínicos (baixa estatura e puberdade precoce central), também não se encontrou associação significativa ( $p=0,17$ e $p=0,82$, respectivamente).

Uma vez que já é conhecido o impacto dos esteróides no crescimento e desenvolvimento puberal, prosseguiu-se a avaliação, dividindo os pacientes em categorias de acordo com a dose do glicocorticóide: elevada (acima de 15 $\mathrm{mg} / \mathrm{m}^{2} / \mathrm{dia}$ ) e normal (até $15 \mathrm{mg} / \mathrm{m}^{2} / \mathrm{dia}$ ). Verificou-se que $15(51,7 \%)$ pacientes utilizaram doses elevadas de glicocorticóide e 14 (48,3\%) utilizaram doses normais. Nesse estudo, não se observou correlação entre as doses de glicocorticóide (elevada versus normal) e a ocorrência de baixa estatura $(p=0,1)$ ou de puberdade precoce central $(p=0,6)$. A mesma análise foi realizada excluindo-se os pacientes 
com doses abaixo de $10 \mathrm{mg} / \mathrm{m}^{2} / \mathrm{dia}$ (apenas 4) e o resultado foi semelhante. Doses elevadas não se associaram ao genótipo $(p=0,6)$ ou à forma clínica $(p=0,13)$ (APÊNDICE D - Tabela 6).

Considerando-se que a dose nos primeiros anos de vida foi significativamente maior nos perdedores de sal, criou-se duas categorias de dose de hidrocortisona ao longo do tempo de tratamento: dose (ou mHIDROC) dos dois primeiros anos e dose (ou mHIDROC) dos demais anos de tratamento. Supondo-se que uma dose maior nos primeiros anos de vida pudesse afetar o crescimento e/ou impedir a puberdade precoce, analisou-se a correlação da freqüência de PPC e de baixa estatura com com as categorias de dose de hidrocortisona ao longo do tratamento. Não foi observada correlação entre os desfechos de crescimento e puberdade e as doses de hidrocortisona em nenhum período do tratamento. A dose também não variou entre os grupos de mutação (APÊNDICE D - Tabela 7).

Não houve correlação entre a dose de hidrocortisona e o escore-z de estatura final $(p=0,46)$. Nos perdedores de sal, a dose dos primeiros anos ou a dose dos demais anos também não influenciaram a estatura ( $p=0,67$ e $p=0,38)$.

Todos os pacientes classificados como perdedores de sal receberam fludrocortisona, exceto três, que iniciaram o acompanhamento após os dois primeiros anos de vida. Nenhum paciente classificado como virilizante simples recebeu mineralocorticóide.

O uso da fludrocortisona não influenciou a dose de hidrocortisona como era esperado $(p=0,51)$. Nos pacientes que faziam uso de mineralocorticóide, não se constatou diferenças nas doses de glicocorticóide utilizadas $(p=0,59)$.

Os dados brutos da análise estatística acima descritos encontram-se no APÊNDICE D. 


\subsection{OUTROS DESFECHOS}

Um paciente perdedor de sal evoluiu com síndrome de Cushing e hipertensão arterial após manipulação inadequada da hidrocortisona por alguns meses. Realizado desmame do corticóide; entretanto, mesmo após a resolução do quadro de Cushing, a criança manteve o quadro de hipertensão arterial, necessitando do uso de dois anti-hipertensivos para controle. A fludrocortisona foi suspensa. Outras causas de hipertensão foram descartadas.

Uma paciente evoluiu com hematocolpo por complicações tardias da vaginoplastia. Tinha baixa adesão à terapêutica com dilatadores vaginais (velas de Hegar).

Duas pacientes, irmãs, com mais de 50 anos, foram submetidas à adrenalectomia bilateral na puberdade.

Um paciente foi diagnosticado com tumor de restos adrenais aos 7 anos.

Um paciente de diagnóstico tardio portador da forma virilizante simples com cariótipo 46, XX e Prader $V$ permaneceu no sexo social masculino por opção da família. 


\section{DISCUSSÃO}

O estudo em questão avaliou as características e os desfechos clínicos dos pacientes portadores de hiperplasia adrenal congênita forma clássica acompanhados no HUB, e suas possíveis associações com o genótipo. Trata-se de estudo retrospectivo, que possibilitou também avaliar, com base em registros de prontuários, alguns desfechos relacionados ao tratamento com glicorticóides ao longo do tempo de seguimento de uma série de casos do Distrito Federal.

A maior parte da amostra recebeu o diagnóstico antes da implementação da triagem neonatal, o que explica em parte o encaminhamento tardio de pacientes com a forma virilizante simples para um centro especializado. Os benefícios da triagem neonatal já estão bem estabelecidos. O método é suficientemente específico e sensível para a detecção de quase todos os casos portadores da forma clássica e busca impedir o registro inapropriado do gênero da criança, além de reduzir a mortalidade e a morbidade (3, 9).

Observou-se que as concentrações plasmáticas de 17-hidroxiprogesterona (17OHP) encontravam-se anormalmente elevadas, porém abaixo do esperado para a forma clássica da HAC. Esse fato não comprometeu os critérios para inclusão, uma vez que o diagnóstico clínico foi confirmado ao longo do tempo de seguimento e/ou pelo genótipo, em todos os pacientes. Verificou-se que, muitas vezes, houve instituição do tratamento com glicocorticóide antes da coleta de exames diagnósticos que não eram realizados de rotina no HUB, como a 17OHP, o que é justificável diante da gravidade do quadro de insuficiência adrenal nos primeiros meses de vida. Além disso, é importante destacar que alguns pacientes iniciaram o acompanhamento no HUB na década de 1990, ou mesmo no final de década de 1980, quando ainda não haviam sido criados os serviços de referência em Endocrinologia no Hospital Universitário. O ambulatório de Endocrinologia Pediátrica foi iniciado no ano de 2000 e o de Gônadas e Adrenais em 2002.

A análise molecular não é essencial, mas confirma o defeito genético, auxilia o aconselhamento e fecha o diagnóstico em casos duvidosos (9). A correlação genótipo-fenótipo e a avaliação do perfil de mutações dos pacientes desse estudo foi descrita previamente pelo mesmo grupo de pesquisa e foi apresentada em dissertação de mestrado de Araújo, em 2013 (12). Constatou-se boa correlação 
genótipo-fenótipo, de aproximadamente 70\%, semelhante às descritas previamente por outros autores, corroborando a eficácia da estratégia metodológica empregada para o diagnóstico molecular. Interessantemente, não se observou associação entre a forma clínica e os grupos de mutação. Entretanto, houve melhor correlação genótipo-fenótipo para as mutações mais graves, o que está de acordo com os efeitos fisiopatológicos de defeitos enzimáticos graves, que levam quase sempre à perda de sal. Embora aparentemente paradoxal, esse resultado está de acordo com as descrições da literatura (6). É importante ressaltar que o diagnóstico molecular pode se tornar uma importante ferramenta permitindo reclassificações para casos duvidosos, como foi feito nesse estudo.

No consenso sobre a deficiência da 21-hidroxilase da Sociedade Européia de Endocrinologia Pediátrica e da Sociedade de Lawson Wilkins de Endocrinologia Pediátrica, os objetivos do tratamento são definidos: repor adequadamente a deficiência de esteróides e, ao mesmo tempo, prevenir o excesso dos hormônios sexuais adrenais e de glicocorticóides, evitando a virilização, melhorando o crescimento e protegendo a fertilidade (9).

Em relação aos desfechos clínicos ao longo do seguimento, notou-se que a pubarca precoce esteve presente em um número expressivo de pacientes $(n=20$, $86,9 \%$ do total de pacientes), tanto virilizantes simples quanto perdedores de sal, 0 que leva a questionar a adesão à terapia com glicocorticóide. Apesar disso, a idade da menarca foi normal, porém mais cedo do que a média mundial de 13 anos (14).

A puberdade precoce central é um diagnóstico não raro na hiperplasia adrenal congênita e sua etiologia está relacionada à exposição precoce do eixo hipotálamohipófise-gônadas aos andrógenos adrenais e sua conseqüente ativação (20). Neste estudo, a PPC foi mais prevalente nos indíviduos com a forma virilizante simples, 0 que provavelmente está associado ao seu diagnóstico e início de tratamento tardios.

Uma meta-análise de 18 trabalhos sobre crescimento na HAC revelou que a média final do escore-z é -1,37 DP, provando que a maioria dos portadores perde estatura final (21). No presente trabalho, o grupo de perdedores de sal atingiu uma estatura final melhor (-1,17 DP), o que não se verificou no grupo de virilizantes simples em que todos os pacientes avaliados evoluíram com baixa estatura. Acredita-se que diagnóstico e tratamento precoce foram cruciais no prognóstico de estatura final desses casos. 
Embora não se tenha encontrado correlação estatisticamente significativa entre a ocorrência de baixa estatura e a mHIDROC, sabe-se que o efeito cumulativo diário de glicocorticóide prejudica o crescimento linear. A ausência de associação entre esses parâmetros pode estar relacionada ao reduzido tamanho da amostra, que, para essa análise, incluiu apenas pacientes que haviam atingido a estatura final, isto é, 16 indivíduos. Os glicorticóides interferem na cascata de sinalização intracelular induzida pelo hormônio de crescimento $(\mathrm{GH}) /$ fator de crescimento insulina-símile tipo 1 (IGF-1) tanto no hipotálamo, quanto na hipófise e em tecidosalvo. Ademais, afetam a liberação do hormônio, a sinalização e a tradução gênica e o processamento do mRNA. O excesso de esteróides leva a uma queda na resposta do $\mathrm{GH}$ ao GHRH (hormônio liberador do hormônio de crescimento) e a uma elevação paradoxal do IGF-1, criando um estado de resistência ao GH. O balanço normal do cálcio nos intestinos e rins é também afetado, interferindo nas interações entre osteoclastos, osteoblastos e condrócitos $(22,23)$. Assim, faz-se necessário maior tempo de seguimento dos sujeitos estudados para confirmação dos resultados de estatura final.

A queda na velocidade de crescimento parece ser o indicador mais sensível do excesso de glicocorticóides em curto/médio prazo. Alguns pesquisadores demonstraram que a velocidade diminuía quando a dose de hidrocortisona era de 25 $\mathrm{mg} / \mathrm{m}^{2} / \mathrm{dia}$ comparada com a dose de $15 \mathrm{mg} / \mathrm{m}^{2} / \mathrm{dia}(24)$.

Vários estudos têm demonstrado que o efeito negativo do excesso de andrógenos no crescimento e na maturação esquelética não ocorre no início da vida. Em dois deles realizados na Suécia e na Holanda, crianças com diagnóstico tardio ou que receberam subdoses de glicocorticóide não apresentaram sinais de virilização ou aceleração do crescimento até 12 meses de vida, sugerindo uma relativa resistência aos andrógenos nesta fase $(25,26)$. Entretanto, no primeiro ano de vida foi observado que doses elevadas de hidrocortisona tinham um impacto negativo no crescimento (27). A dose preconizada na infância é de $10-15 \mathrm{mg} / \mathrm{m}^{2} / \mathrm{dia}$, podendo chegar até $25 \mathrm{mg} / \mathrm{m}^{2} / \mathrm{dia}$ (9). Na amostra estudada, foi constatado que as doses dos primeiros anos de vida eram significativamente maiores, mas não se comprovou uma associação positiva entre a dose e a ocorrência de baixa estatura. O resultado pode ser explicado pelas limitações de tamanho da amostra ou do método, no que diz respeito principalmente à medida da "carga" de glicocorticóide ao longo do tratamento. 
Ademais, entre as idades de 8 e 14 anos, já foi comprovado um efeito dose dependente de glicocorticóide sobre o crescimento. Nos pacientes com HAC, o pico do estirão ocorre dois anos mais cedo e é menor em relação aos controles (27). Alguns autores explicam que o excesso de glicocorticóide atenua a influência dos hormônios sexuais no estirão do crescimento e permite maior liberação de somatostatina, a qual, por sua vez, inibe a secreção de $\mathrm{GH}$ pela hipófise $(28,29)$. Sugeriu-se, portanto, num estudo posterior, que o efeito deletério da hidrocortisona no crescimento puberal possa ser amenizado se a dose não exceder $17 \mathrm{mg} / \mathrm{m}^{2} / \mathrm{dia}$ nessa faixa etária (30).

Outros fatores determinantes para um bom crescimento são a idade de início do tratamento e uma boa adesão. Pacientes que fazem uso irregular da medicação sofrem períodos de excesso de andrógenos, levando a uma fusão prematura das epífises $(31,32)$.

Além dos glicocorticóides, os mineralocorticóides e a reposição de sal em crianças com a forma perdedora de sal desempenham um papel essencial para um crescimento adequado. Permitem a normalização da atividade de renina plasmática e o balanço de sódio e uma menor dose de glicocorticóide (33).

De maneira geral, observou-se considerável variabilidade no tratamento dos pacientes desse estudo, especialmente no que diz respeito à dose e tipo de glicocorticóide, revelando a grande dificuldade existente no controle clínico e laboratorial, principalmente nos primeiros anos e na puberdade.

Ademais, não foram constatadas associações entre o tratamento e os desfechos clínicos ou o genótipo. O tamanho da amostra pode ter influenciado negativamente o resultado visto que já se conhece os efeitos dos esteróides no crescimento e desenvolvimento. Outros trabalhos falharam igualmente em demonstrar possíveis correlações da dose de glicocorticóide com o genótipo (11).

Em conjunto, os resultados das análises de associação que abordaram o tratamento no presente estudo não apontam para um efeito dos glicocorticóides sobre os desfechos clínicos de crescimento e puberdade, porém necessitam de estudos adicionais. Várias limitações podem ainda ser consideradas, uma vez que a "carga" de glicocorticóides à qual cada indivíduo é exposto ao longo da vida pode ser considerada uma função multivariada, que depende essencialmente da idade de início de tratamento, tempo de tratamento, doses, esquemas de administração, adesão, e, provavelmente, sensibilidade individual. Além desses, outros fatores 
podem influenciar a resposta biológica à exposição farmacológica aos glicocorticóides na infância e na vida adulta e carecem de maiores estudos (34).

Dessa maneira, as terapias atuais parecem ser inadequadas em prover uma reposição fisiológica. A droga preconizada é a hidrocortisona na forma de comprimidos ou pastilhas (3), mas não é comercializada no Brasil. Dessa forma, muitos serviços adotam a hidrocortisona manipulada na forma de suspensão oral. Todavia, as apresentações não são bioequivalentes e a forma de suspensão pode ser inadequada para o controle da HAC em virtude da distribuição errática da droga no líquido (3). A prednisolona e a dexametasona também são opções terapêuticas e as doses são tituladas a partir da equipotência de seus efeitos anti-inflamatórios em relação à hidrocortisona. Todavia, a equivalência pode não ser a mesma em relação aos efeitos metabólico e cardiovascular (34).

A variabilidade interindividual quanto às necessidades diárias de glicocorticóide apresenta-se como um desafio adicional no tratamento da HAC e sugere que fatores genéticos possam modular essa resposta. Alguns estudos têm abordado a influência da farmacogenética nas respostas individuais às drogas (35, 36). Algumas tentativas foram realizadas em doenças inflamatórias para avaliar a sensibilidade aos glicocorticóides. Os pesquisadores encontraram que o número de receptores de glicocorticóides (GR) nas células mononucleares do sangue periférico poderia, em parte, predizer a resposta à terapia com glicocorticóide em pacientes com asma, artrite reumatóide, doença inflamatória intestinal e lúpus eritematoso sistêmico (36). A avaliação da sensibilidade aos glicocorticóides em pacientes com insuficiência adrenal primária ou secundária, tal como na HAC, ainda foi pouco explorada.

À despeito de limitações inerentes à metodologia, ao caráter retrospectivo e ao tamanho amostral no presente estudo, até o momento, não havia sido descrito o perfil de pacientes do Distrito Federal, seu comportamento clínico, tratamentos instituídos e resposta clínica. De fato, há poucos relatos de experiências em centros brasileiros na literatura (6), em que se observam diferenças metodológicas e de protocolos de tratamento e interpretação da exposição aos glicocorticóides e de dados de genótipo. Em nível internacional, também predominam estudos descritivos de análises de genótipo e fenótipo em $\operatorname{HAC}(10,11)$.

O presente estudo, além de correlacionar genótipo e fenótipo, por meio de dados de estudo genético robustos (análise da maioria das mutações pontuais 
complementada por pesquisa de rearranjos gênicos), também forneceu informações de cunho longitudinal, com base em amostra de conveniência de um hospital terciário, em ambiente universitário. Embora a maioria dos dados não possam ser extrapolados para a população geral de portadores de HAC, corroboram os dados da literatura, ressaltam as dificuldades no manejo dos pacientes e embasam 0 aperfeiçoamento do tratamento e seu monitoramento. 


\section{CONCLUSÕES}

O presente estudo descreveu os principais aspectos clínicos e suas associações com o genótipo de uma série de 29 pacientes portadores de HAC21OHD forma clássica acompanhados no Hospital Universitário de Brasília, os quais estão sumarizados a seguir:

- Nessa série de casos, houve predomínio da forma perdedora de sal $(n=19)$. A maioria dos pacientes com a forma perdedora de sal era do gênero masculino $(68,4 \%)$ e teve diagnóstico nos primeiros meses de vida (mediana de 1 mês, variando de 0 a 25). A maioria dos pacientes com a forma virilizante simples era do gênero feminino (80\%).

- A mediana da idade da pubarca nos perdedores de sal e virilizantes simples foi 5,5 e 4,3 anos, respectivamente. Observou-se que a maioria das meninas apresentou menarca em idade habitual, porém inferior à média da população geral, que é de 13 anos.

- Puberdade precoce central foi mais prevalente nos indivíduos com a forma virilizante simples $(66,7 \%)$.

- Houve redução da estatura final no grupo virilizante simples $(p=0,03)$, porém a estatura final foi normal no grupo perdedor de sal. É possível que esse fato esteja associado ao início mais tardio do tratamento.

- Foi possível estabelecer correlação genótipo-fenótipo em aproximadamente $70 \%$ dos casos de ambas as formas clínicas, o que está de acordo com a literatura.

- Não houve correlação do grupo de mutações (genótipo mais grave ou moderado) com a forma clínica, porém o grupo com genótipos mais graves apresentou melhor correlação genótipo-fenótipo.

- Não foram observadas associações da ocorrência de puberdade precoce central ou baixa estatura com o genótipo, nem com a mediana 
das doses equivalentes de hidrocortisona utilizadas ao longo do tratamento (mHIDROC).

- Também não foram observadas associações entre o genótipo e as doses de hidrocortisona utilizadas (mHIDROC).

- Observou-se diferença estatisticamente significativa entre as doses de hidrocortisona utilizadas nos 2 anos iniciais de tratamento (mHIDROCi) e nos anos seguintes (mHIDROC-s), como descrito na literatura.

- O uso de fludrocortisona não se associou à diferença nas doses de glicocorticóide utilizadas.

Em conclusão, o presente estudo:

- Corrobora o impacto da HAC na estatura final, principalmente no grupo com a forma virilizante simples;

- Descreve a existência de correlação genótipo-fenótipo em aproximadamente $70 \%$ dos casos nos pacientes do DF, mais freqüente no grupo com perda de sal, semelhante a outros locais.

- Ressalta as dificuldades ainda existentes no manejo da HAC, principalmente no grupo pediátrico e no que diz respeito ao efeito das doses utilizadas de glicocorticóides ao longo de diferentes períodos da vida, seus fatores determinantes, e prognóstico em termos de puberdade e estatura final. 


\section{REFERÊNCIAS}

1. Krone N, Arlt W. Genetics of congenital adrenal hyperplasia. Best Pract Res Clin Endocrinol Metab. 2009; 23:181-192.

2. Nimkarn S, Lin-Su K, New MI. Steroid 21 hydroxylase deficiency congenital adrenal hyperplasia. Endocrinol Metab Clin N Am. 2009; 38:699-718.

3. Speiser PW, Azziz R, Baskin LS, Ghizzoni L, Hensle TW, Merke DP et al. Congenital adrenal hyperplasia due to steroid 21-hydroxylase deficiency: an endocrine society clinical practice guideline. J Clin Endocrinol Metab. 2010; 95(9):4133-4160.

4. Concolino P, Mello E, Zuppi C, Capoluongo E. Molecular diagnosis of congenital adrenal hyperplasia due to 21-hydroxylase deficiency: an update of new CYP21A2 mutations. Clin Chem Lab Med. 2010; 48(8):1057-1062.

5. Mello MP, Bachega TASS, Costa-Santos M, Mermejo LM, Castro M. Bases moleculares da hiperplasia adrenal congênita. Arq Bras Endocrinol Metab. 2002; 46(4): 457-477.

6. Bachega TASS, Billerbeck AEC, Lemos-Marini SHV, Baptista MTM, Mello MP, Guerra G Jr, et al. Estudo multicêntrico de pacientes brasileiros com deficiência da 21-hidroxilase: correlação do genótipo com o fenótipo. Arq Bras Endocrinol Metab. 2004; 48(5): 697-704.

7. New MI, Abraham M, Gonzalez B, Dumic M, Razzaghy-Azar M, Chitayat D, et al. Genotype-phenotype correlation in 1,507 families with congenital adrenal hyperplasia owing to 21-hydroxylase deficiency. PNAS. 2013; 110(7):26112616.

8. Nimkarn S, New MI. Prenatal diagnosis and treatment of congenital adrenal hyperplasia due to 21-hydroxylase deficiency. Mol Cell Endocrinol. 2009; 300: 192-196.

9. Clayton PE, Miller WL, Oberfield SE, Ritzén EM, Sippell WG, Speiser PW. Consensus statement on 21-hydroxylase deficiency from the Lawson Wilkins pediatric endocrine society and the european society for paediatric endocrinology. J Clin Endocrinol Metab. 2002; 87(9):4048-4053.

10. Finkielstain GP, Kim MS, Sinaii N, Nishitani M, Ryzin CV, Hill SC, et al. Clinical characteristics of a cohort of 244 patients with congenital adrenal hyperplasia. J Clin Endocrinol Metab. 2012; 97(12):4429-4438. 
11. Krone N, Rose IT, Willis DS, Hodson J, Wild SH, Doherty EJ, et al. Genotypephenotype correlation in 153 adult patients with congenital adrenal hyperplasia due to 21-hydroxylase deficiency: analysis of the United Kingdom congenital adrenal hyperplasia adult study executive (caHASE) cohort. J Clin Endocrinol Metab. 2013; 98(2):E346-E354.

12. Araújo VGB. Estudo dos genes CYP21A2 e HSD3B2 em indivíduos portadores de hiperplasia adrenal congênita provenientes do Distrito Federal [dissertação]. Brasília: Universidade de Brasília; 2013.

13. Ministério da Saúde (BR), Secretaria de Atenção à Saúde, Programa Nacional de Triagem Neonatal. Brasília: Ministério da Saúde, 2013.

14. Sorensen K, Mouritsen A, Aksglaede L, Hagen CP, Mogensen SS, Juul A. Recent secular trends in pubertal timing: implications for evaluation and diagnosis of precocious puberty. Horm Res Paediatr. 2012; 77:137-145.

15. Macedo DB, Cukier P, Mendonça B, Latronico AC, Brito VN. Avanços na etiologia, no diagnóstico e no tratamento da puberdade precoce central. Arq Bras Endocrinol Metab. 2014;58(2):108-117.

16. Tanner JM, Davies PSW. Clinical longitudinal standards for height and height velocity for North American children. J Pediatr. 1985; 107(3):317-329.

17. Lopez FA, Campos D Jr, organizadores. Tratado de Pediatria - Sociedade Brasileira de Pediatria. Barueri (SP): Manole; 2007. 2210 p.

18. Romanholi DJPC, Salgado LR. Síndrome de Cushing Exógena e Retirada de Glicocorticóides. Arq Bras Endocrinol Metab. 2007; 51(8):1280-1292.

19. Miller WL. The adrenal cortex and its disorders. Clinical paediatric endocrinology. Oxford: Blackwell Science; 2001. 350 p.

20. Hindmarsh PC. Management of the child with congenital adrenal hyperplasia. Best Pract Res Clin Endocrinol Metab. 2009; 23:193-208.

21. Eugster EA, Dimeglio LA, Wright JC, Freidenberg GR, Seshadri R, Pescovitz $\mathrm{OH}$. Height outcome in congenital adrenal hyperplasia caused by 21hydroxylase deficiency: a meta-analysis. J Pediatr 2001; 138:26-32.

22. Hochberg Z. Mechanisms of steroid impairment of growth. Horm Res. 2002; 58(1):33-38.

23. Borges MHS, Pinto ACAR, DiNinno FB, Camacho-Hübner C, Grossman A, Kater CE, Lengyel AM. IGF-1 levels rise and $\mathrm{GH}$ responses to $\mathrm{GHRH}$ 
decrease during long-term prednisone treatment in man. J Endocrinol Invest. 1999; 22(1):12-17.

24. Silva IN, Kater CE, Cunha CDF, Viana MB. Randomised controlled trial of growth effect of hydrocortisone in congenital adrenal hyperplasia. Arch Dis Child. 1997; 77(3):214-218.

25. Thilen A, Woods KA, Perry LA, Savage MO, Wedell A, Ritzen EM. Early growth is not increased in untreated moderately severe 21-hydroxylase deficiency. Acta Paediatr. 1995; 84(8):894-898.

26. Claahsen-van der Grinten HL, Noordam K, Borm GF, Otten BJ. Absence of increased height velocity in the first year of life in untreated children with simple virilizing congenital adrenal hyperplasia. J Clin Endocrinol Metab. 2006; 91(4):1205-1209.

27. Stikkelbroeck NMML, Van't Hof-Grootenboer BAE, Hermus RMM, Otten BJ, Van't Hof MA. Growth inhibition by glucocorticoid treatment in salt wasting 21hydroxylase deficiency: in early infancy and (pre)puberty. J Clin Endocrinol Metab. 2003; 88(8):3525-3530.

28. Bonfig W, bechtold S, Schmidt H, Knorr D, Schwarz P. Reduced final outcome in congenital adrenal hyperplasia under prednisone treatment: deceleration of growth velocity during puberty. J Clin Endocrinol Metab. 2007; 92(5):1635-1639.

29. Devesa J, Barros MG, Gondar M, Tresguerres JAF, Arce V. regulation of hypothalamic somatostatin by glucocorticoids. J Steroid Biochem Mol Biol. 1995; 53(1-6):277-282.

30. Bonfig W, Pozza SBD, Schmidt H, Pagel P, Knorr D, Schwarz HP. Hydrocortisone dosing during puberty in patients with classical congenital adrenal hyperplasia: an evidence-based recommendation. J Clin Endocrinol Metab. 2009; 94(10):3882-3888.

31. Dörr H. Growth in patients with classic congenital adrenal hyperplasia due to 21-hydroxylase deficiency. Horm Res. 2007; 68(suppl5):93-99.

32. Nebesio TD, Eugster EA. Growth and reproductive outcomes in congenital adrenal hyperplasia. Int J Pediatr Endocrinol. 2010; 2010:298937.

33. Kuhnle U, Rosler A, Parreira JA, Gunzcler P, Levine LS, New MI. The effects of long-term normalization of sodium balance on linear growth in disorders with aldosterone deficiency." Acta Endocrinol. 1983; 102(4):577-582. 
34. Debono M, Ross RJ, Newell-Price J. Inadequacies of glucocorticoid replacement and improvements by physiological circadian therapy. Eur $\mathrm{J}$ Endocrinol. 2009; 160:719-729.

35. Moreira RPP, Jorge AAL, Gomes LG, Kaupert LC, Filho JM, Mendonça BB, Bachega TASS. Pharmacogenetics of glucocorticoid replacement could optimize the treatment of congenital adrenal hyperplasia due to 21hydroxylase deficiency. Clinics. 2011; 66(8):1361-1365.

36. Quax RA, Manenschijn L, Koper JW, Hazes JM, Lamberts SWJ, van Rossum EFC, Feelders RA. Glucocorticoid sensitivity in health and disease. Nat Rev Endocrinol. 2013; 9:670-686. 
APÊNDICE A - FICHA DA PESQUISA

\section{Hospital Universitário de Brasília}

\section{Hiperplasia Adrenal Congênita}

Nome:

Registro: Estado Civil Gênero $F($ ) $M($ )

Etnia/raça Profissão: Data de nascimento:

Naturalidade:

Pai: idade: Profissão:

Mãe: idade: Profissão:

Cartão do SUS:

Telefones de contato:

Endereço:

DATA $1^{\mathrm{a}}$ CONSULTA :

QP:

HMA:

Classificação/Forma clínica HAC:

HPP:

- tratamento intra-útero: ( ) sim ( ) não

- desidratação na infância: ( ) sim ( ) não

- antecedentes neonatais:

IG: $P$ : C: PC:

- telarca: pubarca: menarca: sexarca:

- genitália ambígua (classificação de Prader):

- se sim, correção cirúrgica? N( ) S( ) Detalhar:

- virilização (detalhamento):

Outras sintomas/comorbidades:

HF:

- consangüinidade: （ ) sim ( ) não 
- neomortos:

( ) sim ( ) não

- abortos:

( ) sim ( ) não

- casos semelhantes na família: ( ) sim ( ) não

- virilização materna:

- canal familiar: E Pai

( ) sim ( ) não

- Outras doenças:

E Mãe

EA

AE:

- acompanhamento na Psicologia:

- identidade sexual:

- aceitação da doença: (utilizar questionário qualidade de vida específico)

- ciclos menstruais: ( ) regulares ( ) irregulares ( ) amenorréia

- infertilidade:

- Se fértil, quantos filhos?

( ) $\operatorname{sim}$ ( ) não

- Em mulheres, detalhar história obstétrica:

Exame físico da $1^{\mathrm{a}}$ consulta (forma não perdedora de sal):

- Acne: ( ) sim ( ) não

- Hirsutismo: ( ) sim ( ) não

- Escala de Ferriman:

- Alopecia androgênica: ( ) $\operatorname{sim~(~)~não~}$

Avaliação de exames complementares ao diagnóstico:

\begin{tabular}{|c|c|c|}
\hline 17 OHProg & $\begin{array}{c}\text { Valor e Valor de } \\
\text { Referência (unidades) }\end{array}$ & Data, Local e Método \\
\hline 17 OHPreg & & \\
\hline SDHEA & & \\
\hline Androstenediona & & \\
\hline ACTH & & \\
\hline Cortisol & & \\
\hline Testosterona & & \\
\hline DOC & & \\
\hline 11-Deoxicortisol & & \\
\hline LH & & \\
\hline FSH & & \\
\hline Ativ renina & & \\
\hline Aldosterona & & \\
\hline Na & & \\
\hline K & & \\
\hline Cl & & \\
\hline Ca & & \\
\hline P & & \\
\hline PTH & & \\
\hline
\end{tabular}




\begin{tabular}{|c|l|l|}
\hline Alb & & \\
\hline CT & & \\
\hline LDL & & \\
\hline HDL & & \\
\hline TRIG & & \\
\hline Calciúria 24h & & \\
\hline Uréia & & \\
\hline Creatinina & & \\
\hline
\end{tabular}

Idade Óssea:

IC:

PEF: Método:

Cariótipo:

Espermograma:

Ecografia pélvica:

Ecografia testicular:

TC de adrenais:

Densitometria Óssea:

Outros: 
Hospital Universitário de Brasília

Hiperplasia Adrenal Congênita

FICHA DE SEGUIMENTO

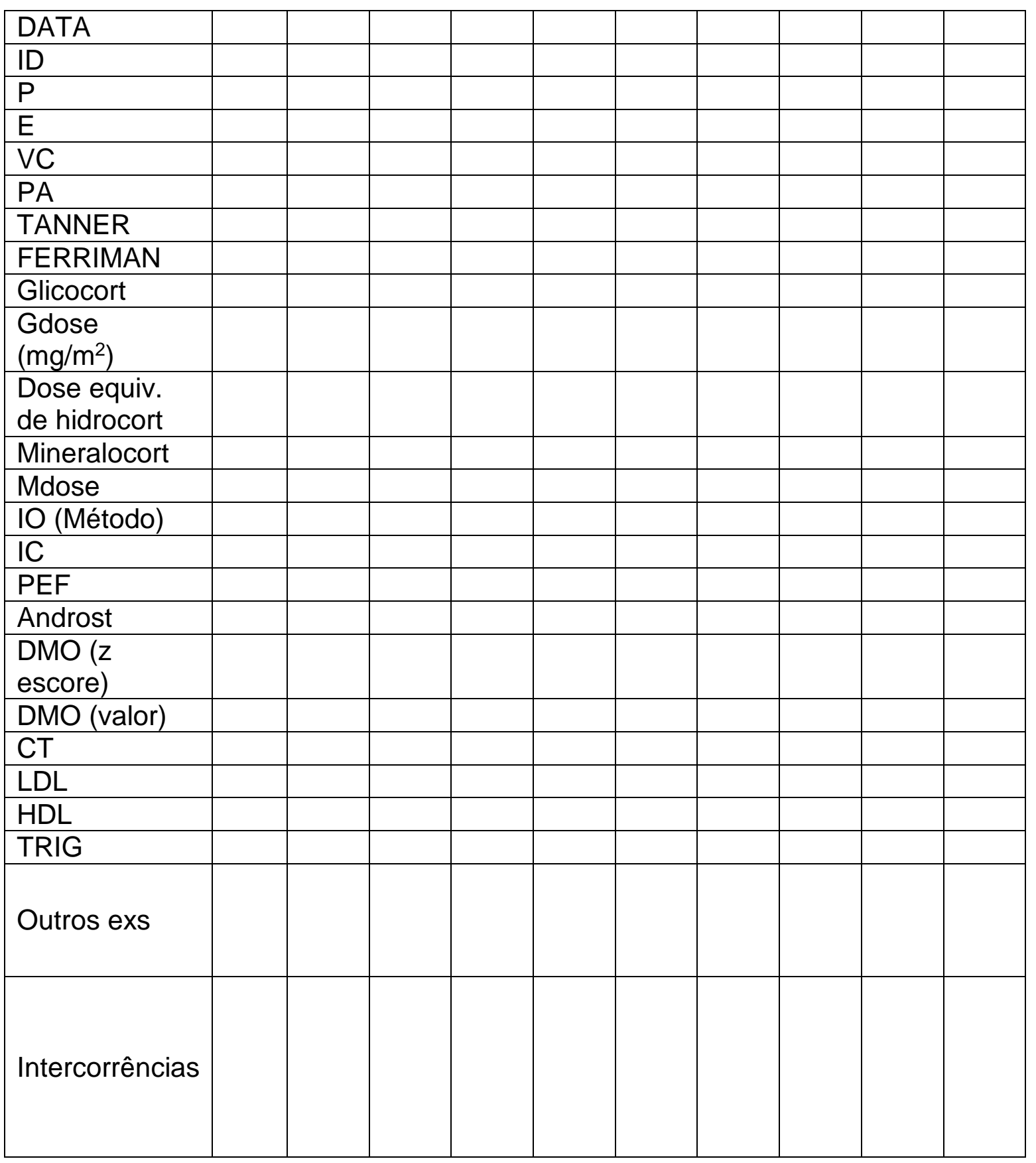




\title{
APÊNDICE B - TERMO DE CONSENTIMENTO LIVRE E ESCLARECIDO
}

\author{
Termo de Consentimento Livre e Esclarecido \\ Faculdade de Ciências da Saúde da Universidade de Brasília - FS/UnB
}

$\mathrm{O}(\mathrm{a})$

senhor(a)

ou o responsável

legal pelo paciente está

sendo convidado a participar da pesquisa: "Estudo do gene CYP21A e a correlação do genótipo com o fenótipo em indivíduos portadores de hiperplasia adrenal congênita por deficiência da enzima 21-hidroxilase" que tem como objetivo caracterizar o perfil das mutações da Hiperplasia Adrenal Congênita e correlacioná-lo com as características clínicas da doença nos pacientes do Hospital Universitário de Brasília (HUB). Para tanto, será necessária uma amostra de sangue que será coletada durante a realização de exames periódicos solicitados para o acompanhamento habitual da doença (Hiperplasia Adrenal Congênita) e que não acarreta riscos à saúde. As informações pessoais a respeito da doença em estudo serão coletadas durante as consultas ou na forma de revisão de prontuário.

A partir do material colhido será realizado um exame de laboratório para definir o diagnóstico molecular da doença.

A provável aplicação prática dos resultados do estudo será no aconselhamento e tratamento de gestações de alto risco dos pacientes envolvidos.

As informações pessoais colhidas para o estudo em consultas ou durante a coleta de sangue não acarretará em tempo adicional de permanência no HUB.

Os pacientes ou responsáveis terão a qualquer momento as informações sobre possíveis riscos e benefícios da pesquisa, para que não fique nenhuma dúvida, e que a qualquer momento o paciente ou responsável poderá desistir da participação no estudo ou se recusar a responder qualquer questão que traga constrangimento sem que haja prejuízo ao tratamento nesta instituição.

No caso de dúvida, o sr (a) poderá entrar em contato com a pesquisadora Renata Santarem de Oliveira (médica) nos telefones 34485234 (Pediatria) ou 99877786. 
Se tiver alguma consideração ou dúvida sobre a ética da pesquisa, entre em contato com o Comitê de Ética em Pesquisa (CEP) da Faculdade de Ciências da Saúde da UnB: 31071947.

O resultado do exame será confidencial e em nenhum momento o nome do paciente irá aparecer. Ademais, todas as informações ficarão sob a guarda da pesquisadora Renata Santarem de Oliveira.

Os dados coletados serão utilizados somente para pesquisa e os resultados serão veiculados através de artigos científicos em revistas especializadas e/ou em encontros científicos e congressos, sem nunca tornar possível a identificação do paciente.

O termo de consentimento se encontra redigido em duas vias, sendo uma para o participante e outra para o pesquisador.

Declaro que, após convenientemente esclarecido pelo pesquisador e ter entendido o que me foi explicado, consinto em participar da presente pesquisa.

\section{Data 1 \\ Assinatura do paciente ou responsável}

Paciente:

Responsável Legal:

Natureza (parentesco, tutor):

Fone: ( )

Data_

Data 1

Assinatura do(a) pesquisador(a)

Vitor Guilherme Brito de Araújo

Renata Santarem de Oliveira

Ana Cristina de Araújo Bezerra 


\section{APÊNDICE C - MÉDIAS ANUAIS EM EQUIVALENTE DE HIDROCORTISONA}

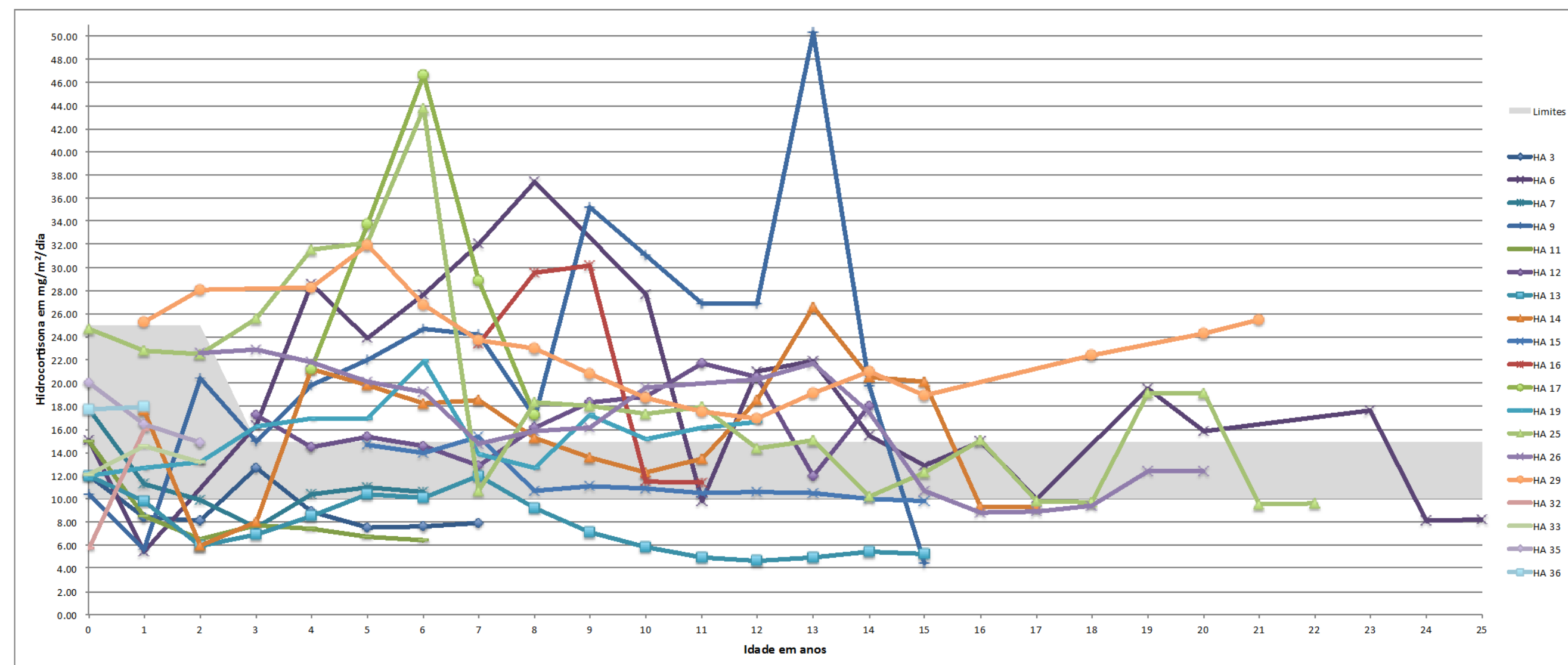

Figura 9. Médias anuais da dose em equivalentes de hidrocortisona nos perdedores de sal ao longo do acompanhamento. 


\section{APÊNDICE C - MÉDIAS ANUAIS EM EQUIVALENTE DE HIDROCORTISONA}

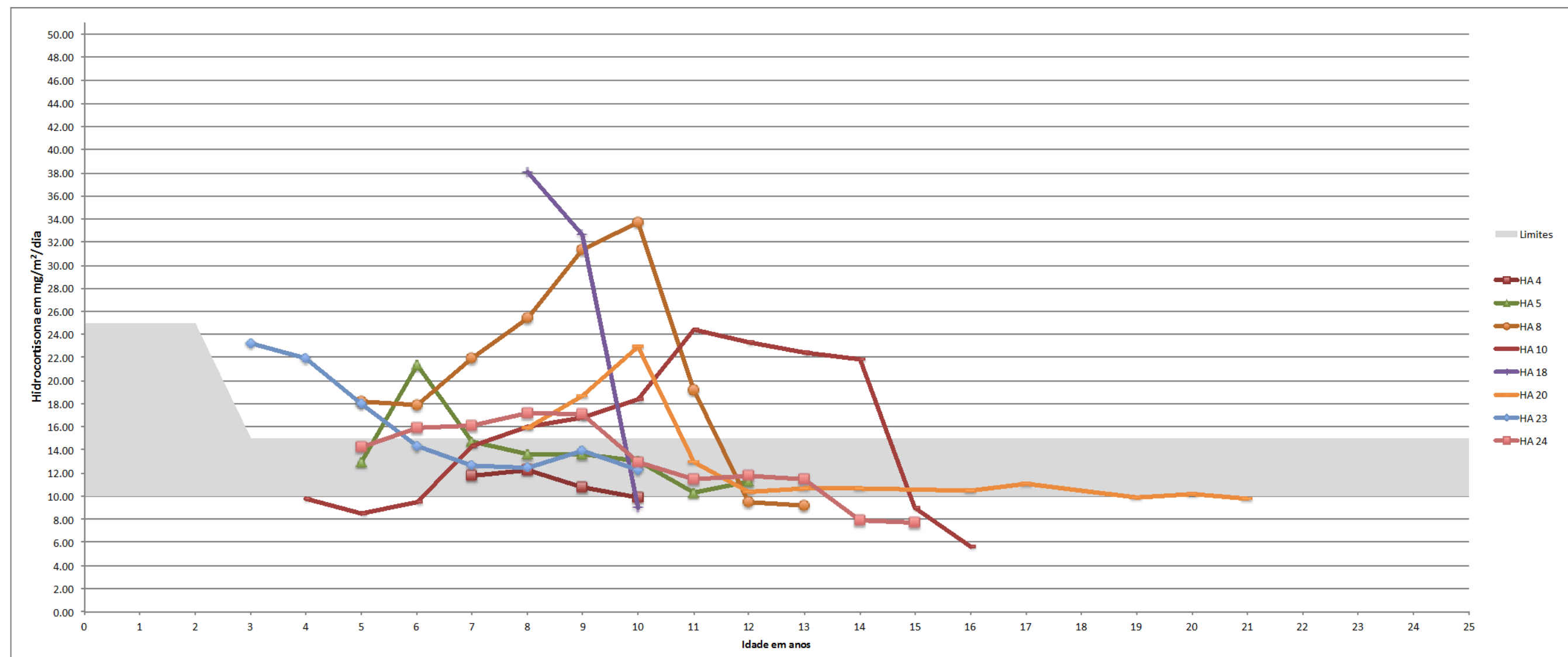

Figura 10. Médias anuais da dose em equivalentes de hidrocortisona nos virilizantes simples ao longo do acompanhamento. 
APÊNDICE C - MEDIANA DAS DOSES EM EQUIVALENTES DE HIDROCORTISONA (MHIDROC)

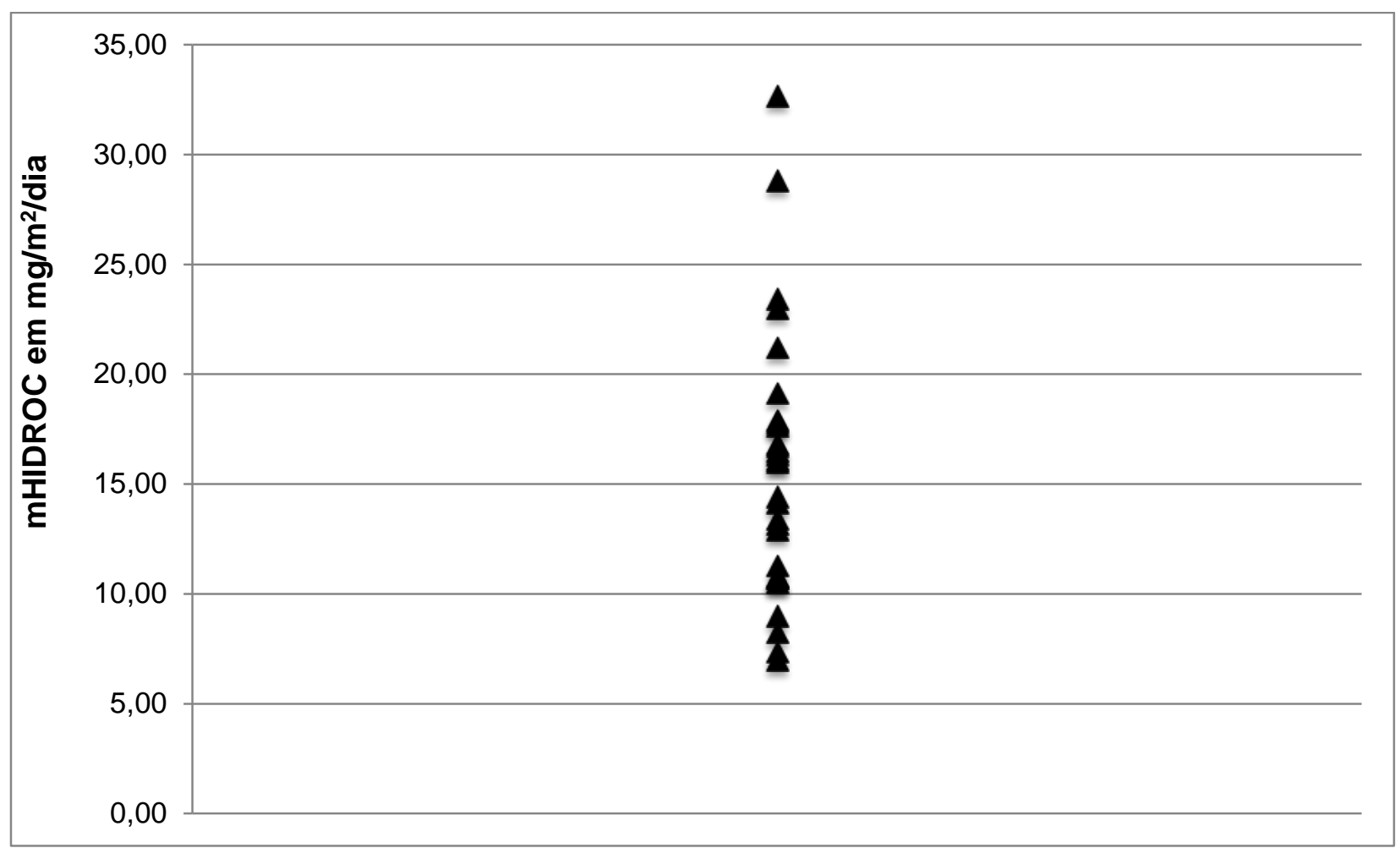

Figura 11. Distribuição da mediana das doses em equivalentes de hidrocortisona (mHIDROC) de cada paciente. 


\section{APÊNDICE D - ANÁLISE ESTATÍSTICA DO TRATAMENTO}

Tabela 6 - Doses equivalentes de hidrocortisona ao longo do tratamento (mHIDROC) conforme a forma clínica e a ocorrência de baixa estatura e puberdade precoce central em pacientes com a forma clássica de hiperplasia adrenal por deficiência da 21 hidroxilase

\begin{tabular}{|c|c|c|c|c|c|c|c|c|}
\hline & \multicolumn{2}{|c|}{ Grupo de mutações } & \multicolumn{2}{|c|}{ Forma clínica } & \multicolumn{2}{|c|}{ Baixa Estatura } & \multicolumn{2}{|c|}{ Puberdade Precoce Central } \\
\hline & 1 & 2 & PS & VS & Presente & Ausente & Presente & Ausente \\
\hline \multicolumn{9}{|l|}{ Hidrocortisona } \\
\hline Mediana & 16,3 & 16,4 & 16,8 & 12,1 & 12,9 & 16,8 & 13,7 & 16,7 \\
\hline Mínimo/máximo & $7,01 / 23,4$ & $12,9 / 16,8$ & $7,01 / 23,4$ & $10,7 / 16$ & $10,7 / 23,4$ & $7,01 / 23,0$ & $10,7 / 23,4$ & $7,01 / 23,0$ \\
\hline$p^{*}$ & \multicolumn{2}{|c|}{0,62} & \multicolumn{2}{|c|}{0,52} & \multicolumn{2}{|c|}{0,17} & \multicolumn{2}{|c|}{0,82} \\
\hline Dose elevada $^{1}$ & $10(66,7 \%)$ & $5(33,3 \%)$ & $12(80 \%)$ & $3(20 \%)$ & $3(30 \%)$ & $7(70 \%)$ & $4(33,3 \%)$ & $8(66,6 \%)$ \\
\hline Dose normal $^{2}$ & $8(57,1 \%)$ & $6(42,9 \%)$ & $7(50 \%)$ & $7(50 \%)$ & $5(83,3 \%)$ & $1(16,7 \%)$ & $3(50 \%)$ & $3(50 \%)$ \\
\hline$p^{*}$ & \multicolumn{2}{|c|}{0,6} & \multicolumn{2}{|c|}{0,13} & \multicolumn{2}{|c|}{0,1} & \multicolumn{2}{|c|}{0,6} \\
\hline
\end{tabular}

${ }^{1}$ Grupo em que a mediana foi acima de $15 \mathrm{mg} / \mathrm{m}^{2} / \mathrm{dia}$

2 Grupo em que a mediana foi abaixo ou até $15 \mathrm{mg} / \mathrm{m}^{2} / \mathrm{dia}$

* Valor $p$ obtido pelo teste exato de Fisher ou $x^{2}$ 


\section{APÊNDICE D - ANÁLISE ESTATÍSTICA DO TRATAMENTO}

Tabela 7 - Análise comparativa entre as doses equivalentes de hidrocortisona ao longo do tratamento (mHIDROC) entre grupos de mutação, ocorrência de baixa estatura e de puberdade precoce central em pacientes com a forma perdedora de sal da hiperplasia adrenal por deficiência da 21-hidroxilase

\begin{tabular}{|c|c|c|c|}
\hline & Grupo de mutações & Baixa Estatura & Puberdade Precoce Central \\
\hline Hidrocortisona & $p^{*}$ & $p^{*}$ & $p^{*}$ \\
\hline De todos os anos (mHIDROC $\left.{ }^{1}\right)$ & 0,46 & 0,68 & 0,31 \\
\hline Dois primeiros anos (mHIDROC-i²) & 0,7 & 0,51 & ** \\
\hline Após dois anos (mHIDROC-s³) & 0,35 & 0,68 & 0,41 \\
\hline Dose elevada ${ }^{4} x$ dose normal ${ }^{5}$ & 1 & 0,5 & 0,46 \\
\hline
\end{tabular}

${ }^{1}$ Mediana das doses equivalentes de hidrocortisona ao longo do tratamento

2 Mediana das doses equivalentes de hidrocortisona ao longo dos 2 anos iniciais de tratamento

${ }^{3}$ Mediana das doses equivalentes de hidrocortisona ao longo dos anos seguintes de tratamento

${ }^{4}$ Grupo em que a mediana foi acima de $15 \mathrm{mg} / \mathrm{m}^{2} / \mathrm{dia}$

${ }^{5}$ Grupo em que a mediana foi abaixo ou até $15 \mathrm{mg} / \mathrm{m}^{2} / \mathrm{dia}$

* Valor $p$ obtido pelo teste exato de Fisher ou $x^{2}$

** Não foi possível realizar a comparação (nenhum paciente que tinha dados da dose dos primeiros anos apresentou PPC) 


\title{
ANEXO A - PARECER DO COMITÊ DE ÉTICA EM PESQUISA
}

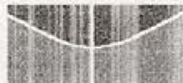 \\ Universidade de Brasília \\ Faculdade de Ciências da Saúde \\ Comitê de Ética em Pesquisa - CEP/FS
}

\section{PROCESSO DE ANÁLISE DE PROJETO DE PESOUISA}

Registro do Projeto no CEP: 112/11

Titulo do Projeto: "Estudo molecular de genes relacionados ao diagnóstico, evolução e resposta ao tratamento em individuos portadores de hiperplasia adrenal congênita"

Pesquisadora Responsável: Vitor Guilherme Brito de Araújo

Data de Entrada: 29/08/11

Com base na Resolução 196/96. do CNS/MS, que regulamenta a ética em pesquisa com seres humanos, o Comitê de Ética em Pesquisa com Seres Humanos da Faculdade de Ciências da Saúde da Universidade de Brasília, após análise dos aspectos éticos e do contexto técnico-científico, resolveu APROVAR o projeto $112 / 11 \mathrm{com}$ o título: "Estudo molecular de genes relacionados ao diagnóstico, evolução e resposta ao tratamento em individuos portadores de hiperplasia adrenal congênita", analisado na $8^{\text {a }}$ reunião ordinária realizada no dia 20 de outubro de 2011.

O pesquisador responsável fica, desde já, notificado da obrigatoriedade da apresentação de um relatório semestral e relatório final sucinto e objetivo sobre o desenvolvimento do Projeto, no prazo de I (um) ano a contar da presente data (item V11.13 da Resolução 196/96).

Brasilia, 25 de outubro de 2011.

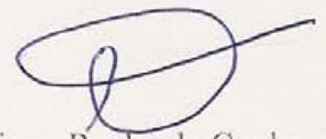

Thiago Rocha da Cunha

Vice-Coordenador do CEP-FS/UnB 
Tabela 8 - Genótipos*

\begin{tabular}{|c|c|c|c|c|c|}
\hline Paciente & Genótipo & MLPA & Quimera & Grupo de mutações & Correlação \\
\hline HA 3 & Q318X/Dup frameshift & Duplicação frameshift exon 4-6 & & 1 & $\operatorname{sim}$ \\
\hline HA 4 & Q318X/Dup exon 6 & Duplicação exon 6 heterozigose & & 1 & $\operatorname{sim}^{1}$ \\
\hline HA 5 & I172N/Q318X & Confirmou mutações sequenciadas & & 2 & $\operatorname{sim}$ \\
\hline HA 6 & P30L-quimera/Del total & Deleção total do gene; confirmou mutação sequenciada & $\mathrm{CH} 9$ em heterozigose & 1 & $\operatorname{sim}$ \\
\hline HA 7 & Q318X/Leu12Met & Confirmou mutação sequenciada Q318X & & 1 & $\operatorname{sim}$ \\
\hline HA 8 & P30L/Del exon 1 & Quimera - fusão da região do exon 1 & $\mathrm{CH} 4$ em homozigose & 1 & não \\
\hline HA 10 & I172N/Q318X & Confirmou mutações sequenciadas & & 2 & $\operatorname{sim}$ \\
\hline HA 11 & Ser269Thr/Del exon 8 & Deleção exon 8 heterozigose & & 2 & não \\
\hline HA 12 & V281L/Ser494Asn/Del exon 8 & Deleção exon 8 heterozigose & & 2 & inconclusivo \\
\hline HA 13 & ND & Duplicação exon 1-6/Deleção do exon 8 & & 1 & $\operatorname{sim}$ \\
\hline HA 14 & F306+t +V281L/Asp184Glu/Del exon 3-6 & Deleção 3-6/Duplicação exon 1 e 8 & & 1 & $\operatorname{sim}$ \\
\hline HA 15 & I2 Splice hemizigose/Del exon 3-6 & Deleção exon 3-6 & & 1 & $\operatorname{sim}$ \\
\hline HA 17 & heterozigoto I2Splice/heterozigoto R356W & normal & & 1 & $\operatorname{sim}$ \\
\hline HA 18 & Ser269Thr/P453S/Dup exon 6 & Duplicação do exon 6 heterozigose & & 2 & inconclusivo \\
\hline HA 19 & I2Splice/Arg480Leu/Del exon 8 & Deleção exon 8 heterozigose & & 1 & $\operatorname{sim}$ \\
\hline HA 20 & I2Splice & normal & & 1 & $\operatorname{sim}$ \\
\hline HA 23 & I2Splice & sem MLPA & & 1 & $\operatorname{sim}$ \\
\hline HA 24 & I2Splice & Deleção exon 8 heterozigose & & 2 & $\operatorname{sim}$ \\
\hline HA 25 & Deleção exon 1-3/I2Splice/Ser494Asn & Deleção exon 1-3 (Duplicação do pseudo 1-3) & $\mathrm{CH} 1$ em homozigose & 1 & $\operatorname{sim}$ \\
\hline HA 26 & V281L/Arg445Stop & sem MLPA & & 2 & inconclusivo \\
\hline HA 28 & I172N & sem MLPA & & 2 & $\operatorname{sim}$ \\
\hline HA 29 & Q318X/I2Splice & sem MLPA & & 1 & $\operatorname{sim}$ \\
\hline HA 31 & I172N & sem MLPA & & 2 & $\operatorname{sim}$ \\
\hline HA 32 & Q318X & sem MLPA & & 1 & $\operatorname{sim}$ \\
\hline HA 33 & I2splice/I172N & sem MLPA & & 2 & inconclusivo \\
\hline HA 35 & E6Cluster + Ser269Thr & sem MLPA & & 2 & inconclusivo \\
\hline
\end{tabular}

* Adaptado de Araújo (12). ${ }^{1}$ Paciente reclassificado neste estudo.

\section{ANEXO B - GENÓTIPOS}

